\title{
LOS OBISPOS DE GUATEMALA Y NICARAGUA Y LA CODIFICACIÓN DEL DERECHO CANÓNICO DE 1917: LOS "POSTULATA EPISCOPORUM"
}

\author{
POR \\ CARlos Salinas ARANEdA* \\ Pontificia Universidad Católica de Valparaíso, Chile \\ carlos.salinas@pucv.cl
}

\begin{abstract}
RESUMEN
La redacción del primer Código de Derecho Canónico que tuvo la Iglesia latina fue ordenada por el Papa san Pío X en 1904. La tarea codificadora, empero, no fue sólo obra de un grupo cerrado de expertos, sino que tuvo en cuenta el parecer del episcopado latino, el que fue consultado en dos momentos diferentes; en ambos fueron consultados los obispos de la provincia eclesiástica de Guatemala y Nicaragua. En este trabajo se estudia, a partir de la documentación guardada en el Archivo Secreto Vaticano, el aporte de los obispos de la provincia eclesiástica de Guatemala en la primera consulta, realizada en 1904.
\end{abstract}

PALABRAS CLAVE: Codificación canónica; Código de Derecho Canónico de 1917; arzobispo de Guatemala; provincia eclesiástica de Guatemala; obispo de Nicaragua; Postulata episcoporum.

\section{THE BISCHOPS OF GUATEMALA AND NICARAGUA AND THE 1917 CANON LAW CODIFICATION: "POSTULATA EPISCOPORUM"}

\begin{abstract}
In 1904, Pope Saint Pius X ordered the first draft for the Code of Canon Law that the Latin Church ever had. The codification task, however, was not only the work of a closed group of experts, but it also took into account the considerations of the Latin episcopate that was consulted in two different occasions and, in both times, the bishops of the ecclesiastical province of Guatemala and Nicaragua were consulted. Based on the documents kept at the Vatican Secret Archives, this article studies the contribution of the bishops of the ecclesiastical province of Guatemala in their first request in 1904.
\end{abstract}

KEY WORDS: Canonic codification; 1917 Code of Canon Law; ecclesiastical province of Guatemala; bischop of Nicaragua; Postulata episcoporum.

Recibido/Received 27-02-2012

Aceptado/Accepted $\quad$ 05-09-2015

\section{LA CODIFICACIÓN DEL DERECHO CANÓNICO DE 1917}

El derecho canónico, esto es, el derecho de la Iglesia católica, constituye en ella un elemento esencial, razón por la cual las normas en la Iglesia han existido desde los primeros momentos de su historia en una evolución que ya alcanza los dos mil años. Durante el primer milenio dichas normas se recogieron en colecciones canónicas, de diversa naturaleza y contenido, ${ }^{1}$ que fueron sustituidas en el segundo milenio

* Este artículo forma parte del proyecto de investigación Fondecyt (Chile) 1095074 del que el autor es investigador responsable y cuyo título es: "La contribución de los obispos de América Latina al proceso de formación del Código de Derecho Canónico de 1917". por el Corpus Iuris Canonici, un amplio texto compuesto de cinco colecciones, la primera de las cuales fue el Decreto de Graciano (1140) seguido por las Decretales de Gregorio IX (1234), el más importante de los textos incluidos en dicho Corpus. Lo integraban, además, el Liber sextus de Bonifacio VIII (1298); las Clementinas, una colección ordenada por el

1 Para una historia del derecho canónico en el primer milenio puede verse García y García, A. 1967. Historia del derecho canónico, I: El primer milenio, Salamanca, con abundante bibliografía hasta la fecha de su edición. Más recientemente, con la bibliografía posterior, Ferme, B. E. 1998. Introduzione alla storia delle fonti del diritto canonico, I: II diritto antico fino al Decretum di Graciano. Roma: Pontificia Università Lateranense. 
Papa Clemente $V$ y promulgada en 1317 por su sucesor, Juan XXII; las Extravagantes comunes y las Extravagantes de Juan $X X I I$, colecciones menores -las dos- elaboradas en el siglo XVI por el jurista parisino Jean Chapius. ${ }^{2}$

En la medida que fue pasando el tiempo, junto al Corpus se fue elaborando una abundante legislación complementaria que venía a satisfacer las necesidades que iban originando las nuevas realidades históricas que la Iglesia debía enfrentar, de manera que, en pleno siglo xIX, el conocimiento del derecho de la Iglesia se hacía en extremo difícil, con la consecuente dificultad en su aplicación y la secuela de inobservancia que un tal fenómeno trae consigo. Un postulatum de once obispos franceses durante el Concilio Vaticano I (1869-1870) resulta en este sentido revelador: ${ }^{3}$ "Es una cosa muy evidente y reconocida desde hace mucho tiempo por todos y por todas partes reclamada que es necesario y muy urgente un examen y una refundición del derecho canónico. Porque, como consecuencia de los grandes y numerosos cambios sobrevenidos en las circunstancias y en la sociedad humana, muchas leyes han llegado a ser inútiles o inaplicables o muy difíciles de observar. Se duda, incluso, si numerosos cánones se encuentran aún en vigencia. En fin, a lo largo de tantos siglos el número de leyes eclesiásticas ha crecido de tal manera y ellas forman un tal cúmulo de colecciones que, en cierto sentido, podemos decir que estamos aplastados por las leyes. A consecuencia de esto el estudio del derecho canónico está lleno de dificultades inextricables y casi infinitas; el más vasto campo está abierto a las controversias y procesos; las conciencias están oprimidas por miles de angustias y empujadas al menosprecio de la ley". No fueron los únicos, pues otros obispos se manifestaron en el mismo sentido ${ }^{4} y$, si bien las soluciones que sugerían no fueron coincidentes, algunas de ellas se situaban en la línea de la codificación del derecho canónico, ${ }^{5}$ es decir,

\footnotetext{
2 El Corpus luris Canonici fue objeto de una edición oficial a cargo de una comisión romana cuyos miembros fueron llamados "correctores romanos". Fue instituida por san Pío V (1566-1572) y la edición de los correctores romanos publicada por Gregorio XIII (1572-1585) en 1582. Esta edición no recoge la denominación de Corpus luris Canonici, la que sí aparece en la edición de Lyon de 1671 y en las posteriores. La edición hoy utilizada habitualmente es la de Friedberg, A. E. 1879. Lipsiae. 1959. Graz. Con posterioridad el Corpus fue complementado incorporándose en diversas épocas otros elementos, algunos de los
} cuales sólo en ediciones privadas.

3 Mansi, J. D., Sacrorum conciliorum nova et amplissima collectio, Sacrosancti Oecumenici Concilii Vaticani, 53, 341-342.

4 Además de la intervención señalada en la nota anterior, fueron los postulados suscritos por 37 obispos napolitanos, ibídem, 378-456, esp. 449-450; 15 obispos alemanes, ibidem, 352-378, esp. 355; el episcopado belga, ibídem, 456-461, esp. 460-461; 33 padres de diversas naciones, ibídem, 478-479; los obispos de las provincias eclesiásticas de Quebec y Halifax (Canadá), ibídem., 467; y un grupo de prelados de Italia central, ibídem, 552-553.

5 En relación con el debate antecedente a la codificación canónica, puede consultarse: Anónimo. 1904. "Pio X e la codificazione del diritto canonico". Il Contencioso Ecclesiastico 5: 66-68; Bersani, F. 1917. "Le fonti del diritto canonico prima della codificazione". Rivista di Diritto Ecclesiastico 10: 23-41; Boudinhon, A. 1904. "De la codification du droit canonique". Le Canoniste Contemporain 27: 641-650; 28, 1905: 18-23, 76-83, 139-149, 207-215, 302-309, 473481, 563-568; Calisse, C. 1904. "La codificazione del diritto canonico". Rivista Internazionale di Scienze Sociali 35: 346-365; Rufini, F. 1905. "La codificazione del diritto ecclesiastico", en AA. VV., Studi di diritto in onore di Vittorio Scialoja: II, 353-391. Milano; Villien, A. 1906, 1907, 1908. "Les reformes du droit canonique et les postulata du concile du aplicar al derecho de la Iglesia la nueva modalidad de fijar el derecho que se había desarrollado en el derecho de los Estados a partir del siglo XVIII, la codificación iusracionalista ${ }^{6}$ que, cuando este debate ocurría en el seno del derecho canónico, ya se había materializado en numerosos códigos, incluso en Hispanoamérica. ${ }^{7}$

La tarea de elaborar un Codex luris Canonici que sustituyera al Corpus fue iniciada por el Papa san Pío X (19031914) a poco de haber iniciado su pontificado en los albores del siglo xx. Lo hizo mediante el motu proprio Arduum sane munus, de 19 de marzo de $1904,{ }^{8}$ mediante el cual creó una comisión pontificia encargada de asumir la codificación del derecho de la Iglesia. ${ }^{9}$

La elaboración del Código, sin embargo, no fue tarea de un grupo cerrado de iniciados, sino que, contando con el trabajo de un número importante de expertos bajo la dirección de Pedro Gasparri, ${ }^{10}$ el mismo motu proprio dispuso la intervención de todo el episcopado latino. ${ }^{11}$ De esta manera, una de las principales características del proceso de codificación del derecho canónico de 1917 consistió en la participación, promovida por la misma Santa Sede, del episcopado en la elaboración del Codex Iuris Canonici. Dicha participación, por cierto, la primera realizada históricamente por la Iglesia al emprender la tarea de elaborar un cuerpo legislativo universal, se articuló en dos grandes momentos: el primero, al inicio de los trabajos de codificación, a través de los postulata episcoporum; el segundo, en pleno proceso codificador, cuando se estaba llegando a la fase conclusiva del mismo, a través de las animadversiones episcoporum.

Vaticain". Le Canoniste Contemporaine 29: 65-74, 209-221, 369-384, 449-463, 554-564, 652-659, 712-717; 30: 74-83, 137-147, 220-228, 273-283; 31: 16-23, 207-219, 364-376.

6 Una completa síntesis sobre la codificación del derecho en Guzmán Brito, A. 2007. "El origen y desarrollo de la idea de codificación del derecho", en Guzmán Brito, A. (ed.), El Código Civil de Chile (18552005). Trabajos expuestos en el Congreso internacional celebrado para conmemorar su promulgación: 43-99. Santiago.

Para la codificación civil en Hispanoamérica el más completo y actual trabajo es el de Guzmán Brito, A. 2000. La codificación civil en Iberoamérica. Siglos $X I X$ y $X X$, Santiago, del que hay una segunda edición notablemente ampliada, 2006, con el título Historia de la codificación civil en Iberoamérica. Cizur Menor: Thomson-Aranzadi.

8 Publicado en Acta Sanctae Sedis 36, 1903-1904: 549-551. El motu proprio lleva la fecha 14 de abril de 1904, pero parece que se trata de un error de imprenta, pues en la carta circular Pergratum mihi, fechada el 25 de marzo de 1904, hay una referencia expresa al motu proprio Arduum sane munus. Son de esta opinión, Llobell, J.; de León, E.; Navarrete, J. (1999). Il libro "De processibus" nella codificazione del 1917. Studi e documenti: I, 34. Milano: Giuffrè Editore. Para una historia de la codificación canónica de 1917, por todos puede verse Fantappiè, C. (2008). Chiesa romana e modernità giuridica, I: L'edificazione del sistema canonistico (1563-1903); II: II Codex luris Canonici (1917), con bibliografía actualizada. Milano: Giuffrè Editore.

9 La nómina de sus integrantes en Acta Sanctae Sedis 36, 19031904: 551.

10 Antiguo profesor en el Instituto Católico de Paris, entonces arzobispo titular de Cesarea y secretario de la S. Congregación de Asuntos Eclesiásticos Extraordinarios, a quien se le nombró al mismo tiempo presidente de la Comisión de consultores. Posteriormente sería hecho cardenal.

11 En la decisión cuarta el Papa manifestaba su deseo de que todo el episcopado, conformándose a las reglas que serían dadas en tiempo oportuno, colaboraran y concurrieran a esta obra tan importante: "IV. Volumus autem universum episcopatum, iuxta normas opportune tradendas, in gravissimum hoc opus conspirare atque concurrere". 
De las dos consultas me interesa, de momento, la primera, la que fue llevada a la práctica mediante la circular Pergratum mihi, de la Secretaría de Estado, de fecha 25 de marzo de 1904, enviada a todos los metropolitanos. ${ }^{12}$ En ella se disponía que los arzobispos, después de haber oído a sus sufragáneos y otros ordinarios que debían estar presente en el concilio provincial, debían hacer llegar a la Santa Sede, dentro de los cuatro meses siguientes, en pocas palabras, las principales modificaciones y correcciones que debían hacerse al derecho canónico en vigor. ${ }^{13}$

En la misma circular se comunicaba a los obispos que, por decisión del Santo Padre, los obispos de cada nación tenían la facultad de escoger y enviar a Roma, a su costo, uno o dos especialistas en derecho canónico o teología, que pudiesen formar parte del grupo de consultores; si preferían escoger uno de los que ya habían sido nombrados consultores por los cardenales, podían encargarles que los representara para someter a discusión y defender sus proposiciones en las reuniones de los consultores; incluso, podían nombrar a alguno de su nación que, residiendo fuera de Roma, pudiese, por correspondencia, aportar de alguna manera a los consultores el apoyo de su colaboración.

La respuesta de los obispos del mundo latino fue amplia, contándose en ella la de numerosos obispos latinoamericanos. Se calcula en aproximadamente cinco mil el número de personas que fueron consultadas por lo que, no sin razón, se ha dicho que el trabajo de consulta a los obispos fue como un concilio ecuménico por correspondencia. El numeroso material reunido fue sistematizado en un volumen que permaneció inédito, bajo la dirección del consultor Bernardino Klumper, con el título Postulata episcoporum in ordine digesta. ${ }^{14}$ Posteriormente se agregó un segundo volumen, más breve que el anterior, con sólo 68 páginas, impreso en 1908 con el título Appendix ad postulata episcoporum, elaborado igualmente por Bernardino Klumper ${ }^{15}$ en el que se recogen, probablemente, las respuestas llegadas con retraso, cuando el primero de estos volúmenes ya estaba en prensa. Ninguno de los dos volúmenes llegó a empastarse y su circulación quedó estrictamente restringida a los consultores, de manera que no fueron conocidos fuera de ellos. Preciso es tener presente, sin embargo, que no todos los postulata fueron recogidos por Klumper por lo que la consulta a los documentos originales se hace indispensable para poder conocer con precisión lo sugerido por los obispos; consulta que es igualmente necesaria cuando se trata de aquellos que fueron incorporados a dicho volumen, porque el consultor fue incorporando lo

\footnotetext{
12 Acta Sanctae Sedis 36, 1903-1904: 603-604.

13 Como se ha observado, se solicitó la colaboración del episcopado para que los consultores, con frecuencia hombres más bien teóricos, fuesen iluminados por las condiciones de vida particular en los diferentes países; la consulta era necesaria para asegurar que el nuevo Código tuviese un carácter eminentemente práctico y para que, gracias a las sugerencias de los obispos, se eliminasen todas las imperfecciones del derecho vigente, introduciéndole al mismo tiempo las reformas necesarias. Vetulani, A. 1942. "Codex Juris Canonici", en Dictionnaire de Droit Canonique: III, 920. Paris.

14 Codex Iuris Canonici / Postulata Episcoporum / in ordinem digesta / a / Rmo. P. Bernardino Klumper O. F. M. / Consultore / Romae / Typis Vaticanis / 1905 /, 283 pp. Archivo Secreto Vaticano, Fondo Commissione (Pontificia) per la codificazione del diritto canonico, caja 4. En adelante: Postulata.

15 Archivo Secreto Vaticano, Fondo Commissione (Pontificia) per la codificazione del diritto canonico, caja 6.
}

que de ellos consideraba de utilidad o cambió de colocación las sugerencias. ${ }^{16}$

Como ha sido puesto de relieve, ${ }^{17}$ estos postulata reflejan el sentir del episcopado mundial en lo que se refiere a la codificación y permiten conocer cuáles eran las preocupaciones y los problemas que interesaban al episcopado mundial a los inicios del siglo $x x$, no sólo de orden jurídico, sino también eclesiológico, disciplinar, pastoral, etc.; desde esta perspectiva, los postulata constituyen una útil manera de aproximarse a las realidades de las iglesias locales de la época a partir de unos protagonistas tan directos como son los obispos de cada una de ellas. En ellos se solicitan soluciones que, en no pocos casos, sólo fueron adoptadas por el Concilio Vaticano II y el Código de Derecho Canónico de $1983 .{ }^{18}$ De la provincia eclesiástica de Guatemala enviaron sus postulata el arzobispo de Guatemala y el obispo de Nicaragua, los dos a los que dedico las páginas de este artículo.

\section{LOS OBISPOS DE LA PROVINCIA ECLESIÁSTICA DE GUATEMALA}

En 1904, cuando se hizo la primera consulta, la provincia eclesiástica de Guatemala estaba integrada por el arzobispado de Guatemala y los obispados sufragáneos de Comayagua, San José de Costa Rica, Nicaragua y San Salvador. Arzobispo de Guatemala era Ricardo Casanova y Estrada; obispo de Comayagua era Santiago María Martínez y Cabañas; ${ }^{19}$ obispo de Nicaragua era Francisco Simeón Pereira y Castellón; obispo de San Salvador era Antonio Adolfo Pérez y Aguilar. ${ }^{20}$ El obispado de San José de Costa Rica estaba vacante. ${ }^{21}$ Los dos prelados que enviaron sus

\footnotetext{
16 Al no estar todavía generalizado el uso de la máquina de escribir, la mayoría de los postulata son manuscritos, lo que dificulta su lectura, a lo que hay que agregar el que ellos están escritos en diversas lenguas, porque no todos los obispos usaron el latín para sus respuestas, si bien un número importante usó la lengua oficial de la Iglesia.

17 Llobel, J.; de León, E.; Navarrete, J. 1999: 47-48.

18 Otra circular, esta vez de 6 de abril de 1904, atribuible al secretario de la Comisión, Pedro Gasparri, fue dirigida a los rectores de las universidades católicas para pedirles el concurso "en esta empresa importante y difícil". Circular Perlegisti, en Acta Sanctae Sedis 37, 19041905: 130-131.

19 Santiago María Martínez y Cabañas nació en Juticalpa, el 12 de noviembre de 1842. Fue ordenado presbítero el 29 de enero de 1871. León XIII lo nombró obispo de Comayagua, Honduras, el 13 de marzo de 1902, a la edad de 59 años. La diócesis de Comayagua fue elevada a arquidiócesis por Benedicto XV con el nombre de Tegucigalpa, el 2 de febrero de 1916, siendo el mismo día nombrado su primer arzobispo. Murió siendo arzobispo de Tegucigalpa, el 11 de agosto de 1921, a la edad de 78 años. Cf. en la web Hierarchia Catholica.

20 Adolfo Pérez y Aguilar nació en San Salvador, el 20 de marzo de 1839. León XIII lo nombró obispo de San Salvador el 13 de enero de 1888. No asistió al Concilio Plenario de América Latina celebrado en Roma en 1899. Cuando San Salvador fue elevado a arquidiócesis por san Pío X el 11 de febrero de 1913, fue nombrado su primer arzobispo. Murió siendo arzobispo de San Salvador, el 17 de abril de 1926, a la edad de 87 años. Cf. en la web Hierarchia Catholica.

21 El último obispo había sido Bernardo Augusto Thiel Hoffman, fallecido el 9 de septiembre de 1901. El 1 de junio de 1904, cuando ya se había enviado al arzobispo de Guatemala el texto del motu proprio "Arduum sane munus", san Pio X nombró obispo de San José de Costa Rica a Juan Gaspar Stork, C.M., quien fue consagrado el 24 de agosto de 1904. Es decir, no alcanzó a intervenir en la respuesta a la primera consulta formulada desde Roma. Falleció el 12 de diciembre de 1920 como obispo de San José de Costa Rica. Cf. en la web Hierarchia
} Catholica. 
respuestas a la Santa Sede fueron el arzobispo de Guatemala, Ricardo Casanova y Estrada, y el obispo de Nicaragua, Simón Pereira y Castellón, los dos obispos de quienes ofrezco un rápido bosquejo biográfico.

Ricardo Casanova Estrada nació en Ciudad de Guatemala, el 10 de noviembre de 1844 . Era un hombre de gran cultura; había estudiado derecho y se había titulado de abogado, ejerciendo posteriormente como juez de comercio. Después de haber viajado por Europa y Estados Unidos de Norteamérica, ingresó al seminario cuando tenía 30 años de edad, en septiembre de 1875 . Ordenado presbítero, fue estrecho colaborador del anciano vicario capitular Raoul y Beltrán, ejerciendo como procurador fiscal de la curia diocesana. A la muerte de éste, lo reemplazó durante los seis meses siguientes, hasta que León XIII lo preconizó obispo de Guatemala, con acuerdo del gobierno, el 25 de enero de 1886, siendo consagrado el 25 de julio siguiente. La sede había estado vacante durante cinco años, después de la muerte de su obispo, Piñol y Aycinena, ocurrida en el exilio, en La Habana. Una vez consagrado obispo, se dedicó a restablecer el capítulo catedral, reabrir el seminario y emprendió la visita sistemática de las parroquias.

Los sermones dominicales del prelado empezaron a ser particularmente apreciados por la alta sociedad de la capital, lo que le originó sombras ante el gobierno el que, aprovechando las protestas del prelado contra la introducción, en las escuelas públicas, de la obra de un autor excomulgado como corruptor de las buenas costumbres, el gobierno lo expulsó del país, el 6 de septiembre de 1887. Viajó a Roma para radicarse posteriormente en San José de Costa Rica. Durante los años siguientes, hubo un notable desarrollo de la prensa católica tanto en la capital como en los centros comerciales, y las fiestas del IV centenario del descubrimiento de América fueron ocasión para manifestar la vitalidad de la vida diocesana, a pesar de las vejaciones gubernamentales que, entre otros episodios, había cerrado el seminario, lo que no significó que los seminaristas suspendieran sus estudios, pues los continuaron junto a sacerdotes designados especialmente al efecto.

A pesar de reiteradas peticiones, el parlamento no accedió a autorizar su regreso, hasta que en 1897, ante la agravación de la situación política, el presidente autorizó su regreso, después de diez años de exilio, siendo acogido con gran pompa. El arzobispo reemprendió sus tareas con mucho celo, a pesar de su salud deteriorada, preocupándose particularmente del apostolado entre los indígenas. No asistió al Concilio Plenario de América Latina celebrado en Roma en 1899. Falleció el 14 de abril de 1913 y sus exequias fueron testimonio de su gran popularidad. ${ }^{22}$

Francisco Simeón Pereira y Castellón nació en León, diócesis de Nicaragua, en junio de 1863. Poco se sabe de sus estudios previos al ingreso al seminario. León XIII

22 Segreteria di Stato, Sezione per i Rapporti con gli Stati, Archivio Storico, Affari Ecclesiatici Straordinari, II Periodo, Guatemala, POS 101-132 bis; III Periodo, POS 139-140. Aubert, R. 1988. "Guatemala", en Dictionnaire d'histoire et de géographie ecclésiastique, XXII: 589598. Paris; Juanos, D. 1936. Compendio de historia de la Ciudad de Guatemala, 3ed. Ciudad de Guatemala; Ramírez Colom, J. M. 1913. Reseña biográfica del ilustrísimo y reverendísimo señor arzobispo de Santiago de Guatemala, don Ricardo Casanova y Estrada. Ciudad de Guatemala. Cf. en la web Hierarchia Catholica. aprobó su nombramiento en la sede titular de Diocesarea in Palestina el 29 de octubre de 1895 y coadjutor del obispo de Nicaragua, Francisco de Ulloa y Larios, nombramiento que el 12 de noviembre siguiente se comunicó al gobierno, a pesar de que el obispo Ulloa y algunos canónigos se mostraron contrarios. Al momento de su nombramiento tenía 32 años de edad. El obispo Ulloa se encontraba físicamente incapacitado para gobernar la diócesis, con una parálisis que le impedía hablar y escribir; intérprete de sus gestos era una señora que solía expresar lo contrario de las intenciones del prelado, por lo que el gobierno de la diócesis lo hacían algunos de sus parientes laicos, poco adictos a la Iglesia, quienes opusieron resistencia a la designación del nuevo obispo. Pereira agradeció el nombramiento y, atendidas las dificultades que opusieron los familiares de Ulloa, estuvo pronto a renunciar, pero se le ordenó tomar posesión de la diócesis con todas las facultades otorgadas a Ulloa. Fue consagrado obispo el 26 de julio de 1896 con el aplauso de los sacerdotes celosos de la diócesis. A pesar de las dificultades originadas por los familiares de Ulloa y algunos canónigos, poco después podía informar a Roma de los buenos resultados de su primera visita a la diócesis.

Ante la protesta del obispo coadjutor por la ley de expropiación de los bienes eclesiásticos, el presidente de la República, José Santos Zelaya, ordenó su exilio, lo que aprovecharon los parientes de Ulloa para intentar que éste retomara el gobierno de la diócesis, lo que no le fue concedido. Pudo regresar de su exilio a fines de 1899 . Sucedió al obispo de Nicaragua, Francisco Ulloa y Larios, el 30 de julio de 1902, fecha del fallecimiento de este último. No fue el único exilio que tuvo que padecer, pues en 1905, por haber protestado contra la leyes que prohibían cualquier manifestación religiosa y el uso de hábito talar por la vía pública, fue expulsado por orden el gobierno junto a otros 13 sacerdotes de la diócesis; se refugió en México, para pasar a Panamá, donde se encontró con algunos de sus sacerdotes, y finalmente a Costa Rica. El 18 de julio de 1906, el obispo comunicaba a Roma que, habiendo finalizado su exilio, se encontraba de nuevo en su diócesis.

Hombre de gobierno decidido, pidió a Roma que no se permitiera el regreso a Nicaragua del sacerdote italiano Filippo María Sordini que había viajado a Roma. Sobre el decano, el presbítero Rafael Jerez, escribía a Roma que le parecía más prudente que la Santa Sede no le concediera un título honorífico; de hecho, los antecedentes que envió a Roma sobre este sacerdote, una vez llegados a destino, fueron remitidos al Santo Oficio. Y también informaba a Roma sobre la perversa conducta del canónico Mercedes Reyes, nombrado teólogo sin concurso, a quien había tenido que suspender por desobediencia. Solicitó facultades para conferir la prebenda teologal al sacerdote Canuto Reyes, lo que se le concedió, previo examen ante el obispo. San Pío $X$ lo nombró arzobispo titular de Cyzicus el 2 de diciembre de 1913, y falleció el 29 de enero de 1921; a su muerte, el gobierno ordenó funerales solemnes. ${ }^{23}$

23 Segreteria di Stato, Sezione per i Rapporti con gli Stati, Archivio Storico, Affari Ecclesiatici Straordinari, II Periodo, POS 63-85; III Periodo, POS 86-101. Cf. en la web Hierarchia Catholica. 


\section{LOS POSTULATA DEL ARZOBISPO DE GUATEMALA}

En carta enviada desde Guatemala el 17 de agosto de 1904 al cardenal Rafael Merry del Val, Secretario de Estado de san Pío $X^{24}$ el arzobispo daba cuenta que, después de haber recibido el 25 de abril anterior la carta del cardenal haciendo la primera de las consultas, había remitido a sus obispos sufragáneos dos copias del motu proprio De Ecclesiae legibus in unum redigendis y otro tanto había hecho con la carta circular Pergratum mihi de fecha 25 de marzo. Agregaba que por motivos más o menos válidos dos de los prelados sufragáneos se habían excusado de emitir su parecer; y como de las otras dos diócesis no había recibido la esperada respuesta, aunque había sido expresamente prometida, no podía esperar más si quería responder dentro del plazo. En estas circunstancias, los postulata que enviaba eran por completo de su autoría y responsabilidad.

Cuando ya había enviado a Roma su carta adjuntando sus postulata, llegaron a manos del arzobispo los postulata del obispo de Nicaragua que envió de inmediato a Roma. ${ }^{25}$ Como el obispado de San José de Costa Rica estaba vacante, los obispos que se excusaron debieron ser los de Comayagua, Santiago María Martínez y Cabañas, y San Salvador, Antonio Adolfo Pérez y Aguilar. El vicario capitular del obispado vacante de San José de Costa Rica, si bien nada le impedía hacer sus propias sugerencias, quizá considero oportuno no hacerlo, pues por esos mismos días se había designado al nuevo obispo quien, probablemente, no dispuso de tiempo para responder a Roma oportunamente.

Los postulata del arzobispo de Guatemala se contienen en cuatro páginas y media, tamaño oficio, escritas en latín, en elegante caligrafía. ${ }^{26}$ Se distribuyen en cuatro párrafos extensos, dedicados cada uno de ellos, en el mismo orden, a los siguientes temas: la forma externa del derecho canónico; la promulgación de las leyes eclesiásticas; los impedimentos del matrimonio; y la usura. Los analizaré en el mismo orden.

\section{La forma externa del derecho canónico}

Parecía al arzobispo evidente que el derecho canónico, en su forma externa, tenía necesidad de cambio. Hecha la anterior afirmación, con la que daba inicio a sus ideas, hacía seguidamente un extenso comentario en el que se refería a los diversos modos con que estaba fijado el derecho de la Iglesia, poniendo de relieve las bondades del modelo de la codificación "de los que sus partes o artículos presentan mandatos o declaraciones en estilo breve y preceptivo, cuyo orden aparece más o menos idóneo". Reconocía también que parte de la legislación de la Iglesia estaba recogida en

24 Archivo Secreto Vaticano, Fondo Commissione (Pontificia) per la codificazione del diritto canonico, caja 96.

25 En el texto latino de los postulata del obispo de Nicaragua, se ha agregado a mano, en italiano: "enviado por el arzobispo de Guatemala". No he encontrado la carta con la que, presumiblemente, fueron enviados. Estos postulata se encuentran en Archivo Secreto Vaticano, Fondo Commissione (Pontificia) per la codificazione del diritto canonico, caja 96.

26 Archivo Secreto Vaticano, Fondo Commissione (Pontificia) per la codificazione del diritto canonico, caja 96. colecciones que solo contenían ya constituciones pontificias, ya cánones sinodales, ya resoluciones de las sagradas congregaciones romanas o instrucciones generales a favor de lo espiritual, lo litúrgico o el régimen judicial de la Iglesia, dispuestas solamente en orden cronológico.

Después de recordar que debía ser respetado lo dicho por el Romano Pontífice, en el sentido de tomar consejo de las autoridades de la Iglesia a fin de que las leyes de la Iglesia fuesen reducidas a un solo texto, con un claro orden de distribución, manifestaba su esperanza de que el mundo "gozará de las utilidades de un código o de un cuerpo de códigos informado con un consejo histórico no menos que filosófico, donde nada esté vigente, sino por autoridad práctica y se descubra adaptado a la condición de nuestros tiempos". El arzobispo, además de hacer una velada crítica al estado del derecho canónico vigente, no optaba sólo por un Código, sino que se abría a la posibilidad de diversos códigos que conformarían, en palabras suyas, "un cuerpo de códigos". No fue el único que se planteó en estos términos, aunque hay que reconocer que su idea de varios códigos era más bien incidental, a diferencia de otros dos episcopados que se refirieron expresamente a la posibilidad de que hubiese diversos códigos, supuesta la existencia junto a ellos, de una Ley fundamental de la Iglesia: los obispos de Chile ${ }^{27}$ y los de Bensançon, en Francia. ${ }^{28}$

La codificación como modalidad fijadora del derecho del Estado fue conocida en Guatemala desde temprano, cuando en 1837 empezaron a regir los códigos que Edward Livingston había proyectado, sin éxito, para la Louisiana. El fracaso de los mismos también en Guatemala abrió la necesidad de redacción de nuevos códigos, lo que ocurrió en 1877 cuando entró en vigencia el Código Civil de la República de Guatemala, el mismo año en que también entró en vigencia el Código de Comercio. Otro tanto había ocurrido con anterioridad en los obispados sufragáneos de esta provincia eclesiástica, pues desde 1859 El Salvador tenía su propio Código Civil y desde 1871 lo tenía Nicaragua, que estuvo vigente hasta 1904, precisamente el año en que el arzobispo escribía sus postulata, en que fue sustituido por uno nuevo. Y desde antes, en concreto, desde 1841, Costa Rica tenía un Código General de la República de Costa Rica, que en un mismo texto, comprendía las materias civil, penal y de procedimientos judiciales, esto es, tres códigos en uno solo, que rigió hasta 1888 , año en que entró en vigencia el Código Civil de la República de Costa Rica. Había, así, una larga experiencia acerca de las bondades de fijar el derecho bajo la forma de uno o varios códigos, que el arzobispo conocía por su formación jurídica y por el ejercicio de la abogacía, y que estaba inspirando su apoyo a la codificación canónica. ${ }^{29}$

Concluía estas primeras reflexiones, reconociendo que la misma redacción científica del derecho de la Iglesia mostraría las óptimas condiciones por las que, como se decía, habían sido alabados algunos edictos, preceptos, instrucciones de Pío VII, Gregorio XVI, Pio IX promulgados para el régimen temporal del Estado eclesiástico.

27 Salinas Araneda, C. 2008. "El primer aporte de los obispos chilenos a la codificación del derecho canónico de 1917: los postulata episcoporum". Revista de Estudios Histórico-Jurídicos 30: 317-342.

28 Postulata: 7-8.

29 Guzmán Brito, A. 2006: passim. 


\section{Promulgación de las leyes eclesiásticas}

Tal como lo hiciera en el apartado anterior, el arzobispo empezaba estas nuevas consideraciones con una nueva afirmación: "a favor de las sagradas leyes se desea ciertamente la promulgación en razón de que sea auténtica, permanente, verdaderamente pública, de fácil conocimiento para todos". Ese deseo estaba motivado en un hecho que el arzobispo constataba a continuación y que era expresión de una de las dificultades que presentaba el estudio y el conocimiento del derecho de la Iglesia al tiempo de la codificación: la diversidad de opiniones entre los doctores. Decía el arzobispo Casanova y Estrada que eran "conocidas entre los canonistas las disputas acerca de la fuerza universal de obligar de las decisiones de la Sagrada Congregación del Concilio". Lo que, en cambio, no sucedía con los decretos de la Inquisición, pues por disposiciones de años anteriores se había ido precisando su alcance; para ello el obispo citaba los comentarios a la constitución Apostolicae Sedis, ${ }^{30}$ editados en Roma el año 1883, donde se leía: "a partir de aquí, cuando una ley sea promulgada, los decretos de la Inquisición sólo valen para aquellos a quienes están dirigidos, mínimamente para los otros, o bien después que conste de ellos la legítima promulgación (ap. 31)". También aludía el arzobispo a una sentencia del Santo Oficio del 22 de diciembre de 1880, ${ }^{31}$ que declaraba auténticamente que la sección III, artículo I de la constitución recién citada ${ }^{32}$ comprendía el matrimonio llamado civil, atentado por personas eclesiásticas, "cuya extensión y eficacia universal se percibe de manifiesto". A propósito de esta sentencia, el prelado se cuidaba de aclarar que no le correspondía juzgar sobre la verdad de la misma. ${ }^{33}$

Citaba igualmente el arzobispo los decretos generales de la Sagrada Congregación de Ritos, respecto de los cuales

30 Pío IX, const. Apostolicae Sedis, de 12 de octubre de 1869, que codificó las censuras latae sententiae, Acta Pii IX, V: 55-72, ahora en Gasparri, P. (ed.) 1933-1962. Codicis Iuris Canonici Fontes, Città del Vaticano: Typis Polyglottis Vaticanis, III, 24-31 (en adelante Fontes).

31 S. Congregación del Santo Oficio, "Sentencia Ratisbonen, de 22 de diciembre de 1880". Acta Sanctae Sedis, 15: 536-539, ahora en Fontes: IV, 385-387.

32 El texto de la constitución Apostolicae Sedis, a que se refiere la sentencia es el siguiente: “§ III. Excommunicationes latae sententiae Episcopis sive Ordinariis reservatae. Excommunicationi latae sententiae Episcopis sive Ordinariis reservatae subiacere declaramus: 1 . Clericos in Sacris constitutos vel Regulares aut Moniales post votum solemne castitatis matrimonium contrahere praesumentes; nec non omnes cum aliqua ex praedictis personis matrimonium contrahere praesumentes" [= Excomuniones en las que se incurre de inmediato reservadas a los obispos u ordinarios. Declaramos que quedan reservadas a los obispos u ordinarios las siguientes excomuniones en las que se incurre de inmediato: 1. Los clérigos constituidos en sagrado, ya regulares ya monacales, después del voto solemne de castidad que intenten contraer matrimonio; y ciertamente todos los que intenten contraer matrimonio con alguna de las predichas personas].

${ }_{33}$ El texto de la sentencia al que se refiere el arzobispo es el siguiente: "R. Ad. I. Clericos in sacris constitutos, vel regulares aut moniales post emissum solemne castitatis votum, praesumentes contrahere matrimonium sic dictum civile in locis ubi lex Tridentina de clandestinitate viget, incurrere excommunicationem latae sententiae Episcopis seu Ordinariis reservatam" [= "Respuesta. A la primera duda. Los clérigos constituidos en sagrado, ya sean regulares o monacales después de emitido el voto solemne de castidad, que se atrevan a contraer el matrimonio llamado civil en los lugares en los que rige la ley tridentina acerca de la clandestinidad, incurren en excomunión que no requiere sentencia, reservada a los obispos u ordinarios". reconocía que no podía haber dudas, pues las respuestas o bien las decisiones emitidas en casos particulares, frecuentemente tenían la fuerza de la naturaleza misma de la materia, obligando generalmente; con todo, el prelado reconocía que "puede ser discutible".

Sugería, finalmente, que todas las dudas de cualquier género pudiesen ser disipadas por una colección auténtica de leyes eclesiásticas, editada por la Santa Sede, si es que las disposiciones a las que iban unidas tenían la fuerza de leyes universales; en este caso, la fuente del derecho sería única. Otras decisiones, que eran leyes que interesaban sólo a los que iban dirigidas, podían publicarse en colecciones privadas (Actos de la Santa Sede, compendios, etc.), que constituirían el mejor tesoro de jurisprudencia.

Por de pronto, llama la atención el conocimiento que el prelado tenía de la legislación canónica; es de las pocas propuestas episcopales hechas en este momento de la codificación, al menos de las llegadas a Roma desde América Latina, que apoyaba sus sugerencias con referencias expresas a normas vigentes. Vuelve aquí a proyectarse su formación jurídica. Por otra parte, que el tema sugerido por el prelado de Guatemala era un tema que preocupaba en la Iglesia lo muestra el hecho que no fue el único en sugerirlo, pues en el resumen de los postulata hecho por Bernardin Klumper, ${ }^{34}$ la propuesta de Guatemala aparece junto a las sugerencias de los padres de la provincia de Holanda, los obispos de España, los padres de la provincia de Rouen en Francia, los padres de la provincia de Chile y los de Besançon en Francia. Los mismos obispos de Rouen ${ }^{35}$ pedían que cuando se publicaran las decisiones particulares de las Sagradas Congregaciones se distinguiera cuando las respuestas eran particulares o tenían fuerza de leyes universales.

En derecho canónico la promulgación de la ley es un acto oficial, generalmente de reducida capacidad de divulgación, que fija de manera auténtica el tenor de su texto. La promulgación suele coincidir con el acto de la publicación oficial, pero estos dos actos pueden ser formal y materialmente diferentes y realizados en momentos distintos. Desde el siglo XIII se distinguió claramente la promulgación de su posterior divulgación. La promulgación se hacía en el lugar donde residía el Papa, de ordinario en Roma, y se hacía fijando el documento en un lugar público, como las puertas de las basílicas o de la Cancillería Apostólica, la Penitenciaría o la Dataría, al tiempo que se acostumbraba leer el documento pontificio en las iglesias u otro lugar público. A partir de 1870 los documentos pontificios se promulgaban mediante la publicación que de los mismos se hacía en los propios oficios o dicasterios y, con frecuencia, especialmente a partir de 1904, es decir, el mismo año en que el arzobispo de Guatemala hacía estas sugerencias, por su inserción en los Acta Sanctae Sedis, aunque no había todavía una norma legal sobre la materia. ${ }^{36}$

El Código se refirió expresamente a la promulgación de las leyes definiendo que "las leyes se instituyen cuando se promulgan" (can. $8 \S 1$ ), repitiendo el célebre dictum de Graciano en su Decreto: "leges instituuntur cum

\section{Postulata: 16 .}

35 Ídem.

36 Cabreros de Anta, M., c.m.f.; Alonso Lobo, A., o.p.; Alonso Morán, S., o.p. 1963. Comentarios al Código de Derecho Canónico: I, 106-110. Madrid: Biblioteca de Autores Cristianos. 
promulgantur". ${ }^{37}$ Agregaba después el lugar en que debía hacerse la promulgación de las leyes dadas por la Sede Apostólica y la vacación de las mismas antes de entrar en vigencia: su promulgación se hacía "mediante su publicación en el Comentario Oficial de los Actos de la Sede Apostólica, a no ser que en casos particulares se prescriba otra forma de promulgación"; su entrada en vigencia se producía "solamente después de pasados tres meses a partir de la fecha que lleva el número de los Actos", a menos que por la naturaleza de la cosa obligasen desde luego o que la misma ley hubiera especial y expresamente establecido una vacación más corta o más larga (can. 9).

En materia de interpretación de la ley, dispuso el Código que "la interpretación auténtica de las leyes compete al legislador o su sucesor y a aquel a quien por los mismos hubiera sido concedida la facultad de interpretar" (can. $17 \S 1$ ). En lo que se refirió al Código de Derecho Canónico, Benedicto XV, mediante el motu proprio Cum iuris canonici, ${ }^{38}$ estableció una Comisión Pontificia de Cardenales para la interpretación auténtica de sus cánones. ${ }^{39} \mathrm{El}$ mismo motu proprio quiso garantizar la estabilidad de lo preceptuado en el Código, regulando con severidad lo concerniente a las nuevas leyes o nuevos decretos generales de las Congregaciones romanas, los que no debían darse sino cuando lo exigiese una necesidad grave de la Iglesia universal. ${ }^{40}$

De esta manera, la sugerencia del arzobispo de Guatemala de que todas las dudas de cualquier género pudiesen ser disipadas por una Colección auténtica de leyes eclesiásticas, editada por la Santa Sede, no se vio materializada en los mismos términos sugeridos por el prelado, pues la Santa Sede no publicó nada de lo que él proponía, pero se vio satisfecha por las publicaciones que privadamente se hicieron de las interpretaciones auténticas hechas al Código por la Comisión encargada de esa tarea. Y se vio superada con las colecciones, también privadas, que se hicieron de la legislación postcodicial, en las que se recogía tanto la legislación general como particular.

\section{Impedimentos matrimoniales}

El tercer párrafo de la respuesta enviada desde Guatemala a Roma estaba dedicado a los impedimentos matrimoniales. Se trató de un párrafo extenso, que se refería a diversos impedimentos respecto de los cuales el prelado daba sus propias opiniones.

37 D. 4 C. 3.

38 De 15 de septiembre de 1917, Acta Apostolicae Sedis 9, 1917: 483-484.

39 De las interpretaciones auténticas del Código emanadas de la Pontificia Comisión establecida por Benedicto XV hay varias colecciones, siendo la más difundida la de Sartori, C.; Belluco, B. 1963. Enchiridion canonicum seu Sanctae Sedis responsiones post editum Codicem luris Canonici datae 1917-1963, 11ed. Roma: Athenaeum Antonianum. Puede verse también, entre otras, hasta 1940, Conte a Coronata, M. o.f.m. cap. 1940. Interpretatio authentica Codicis Iuris Canonici et circa ipsum Sanctae Sedis iurisprudentia 1916-1940. Taurini, Romae: Domus Editorialis Marietti.

40 De la legislación canónica postcodicial la más difundida colección es la de Ochoa, X. 1966-2001. Leges Ecclesiae post Codicem iuris canonici editae, 9 vols. Roma: Ediurcla. El último comprende hasta 1999.

\section{3. a. Eliminación de algunos grados de impedimento de parentesco por consanguinidad y afinidad}

En 1892 la Sagrada Congregación del Santo Oficio había preguntado a los obispos si juzgaban conveniente permitir el matrimonio libremente entre quienes, hasta ese momento, estaban ligados por algún impedimento de parentesco por consanguinidad y afinidad. En concreto: en cuanto a la consanguinidad, la pregunta se refería a quienes estaban unidos por parentesco de consanguididad en cuarto grado; y en cuanto a la afinidad, a los parientes por afinidad lícita en tercer y cuarto grado, y a los parientes por afinidad ilícita en segundo grado. El arzobispo de Guatemala en su comentario, recordaba lo que en esa oportunidad había respondido a Roma: rebajar en esos grados los impedimentos matrimoniales significaba que dichas uniones dejaban de ser pecado, en circunstancias que, en atención a la condición de la sociedad cristiana, era menester mantener la integridad de las costumbres y la santidad del matrimonio. Utilizando un lenguaje más bien ambiguo, no se oponía expresamente a eliminar tales grades de dichos impedimentos, por lo que Klumper, al confeccionar el resumen de los postulata llegados a Roma, lo colocó junto con quienes estaban de acuerdo con su eliminación.

Para entender correctamente la consulta romana y la respuesta del arzobispo es preciso tener presente que el modo de computar los grados de parentesco en derecho canónico era diverso al del derecho romano, que era el que había acogido la totalidad de las legislaciones civiles, diferencia que, en la práctica, significaba que los grados canónicos doblaban a los romanos; de esta manera, los hermanos que, según el cómputo romano se encontraban en el segundo grado de consanguinidad colateral, según el cómputo canónico se encontraba sólo en el primer grado; y los primos hermanos, que en el cómputo romano estaban en cuarto grado de consanguinidad colateral, en el cómputo canónico estaban sólo en el segundo.

\section{3. a. 1. Consanguinidad}

Al tiempo de la codificación, la consanguinidad en línea colateral, que en otro tiempo impedía el matrimonio hasta el séptimo grado -canónico-, se había limitado al cuarto grado en el IV Concilio Lateranense (1215). Esto significaba que no podían contraer matrimonio los hermanos entre sí, los tíos con sobrinos, los primos hermanos entre sí, los primos en segundo grado entre sí y los primos en tercer grado entre sí. La nulidad era por derecho natural sólo en el primer grado -entre hermanos- según muchos teólogos, aunque algunos consideraban que el matrimonio en ese grado, si bien sería gravemente ilícito, no sería nulo atendido sólo el derecho natural. La consulta romana pretendía ver la posibilidad de permitir el matrimonio entre primos en tercer grado. $Y$ ante esta posibilidad el prelado de Guatemala se había opuesto. A decir verdad, no hubo una oposición expresa, pero al recordar lo que había respondido en su momento a Roma, me parece que implícitamente estaba rechazando esa posibilidad.

El Código, sin embargo, redujo el impedimento de consanguinidad al tercer grado -contado a la manera canónica- en la línea colateral (c.1076), esto es, prohibió el matrimonio hasta entre primos en segundo grado entre sí. En todo caso, 
el impedimento de consanguinidad en tercer grado de la línea colateral era de grado menor (c.1042 § $2 n^{\circ} 1$ ), por lo que se dispensaba fácilmente, aunque adoleciese de vicio de obrepción o subrepción (c.1054). En segundo grado de línea colateral, es decir entre primos hermanos o primos en primer grado, se dispensaba con facilidad y no estaba reservado a la Santa Sede, como sí lo estaba el impedimento de consanguinidad en segundo grado mezclado con primero, esto es, tíos con sobrinos, para cuya dispensa, además, se requerían causas más graves. La dispensa de los demás grados quedaba reservada a la Santa Sede. ${ }^{41}$

\section{3. a. 2. Afinidad lícita}

La afinidad lícita, esto es, la que se originaba por cópula lícita, ex matrimonio, dirimía el matrimonio entre el varón y las consanguíneas de la mujer o el de ésta con los consanguíneos de aquél y se extendía, al tiempo de la codificación, hasta el cuarto grado, contado según el modo canónico. Hasta el IV Concilio Lateranense (1215) se prolongaba hasta el séptimo grado, siendo reducido por dicha asamblea conciliar al cuarto grado, disciplina que, en materia de afinidad lícita, conservó el Concilio de Trento (1545-1563) y era la vigente al momento de la codificación. Disputaban los doctores si la afinidad ex copula conjugali dirimía el matrimonio por derecho natural en el primer grado de línea recta, o sea, entre el padrastro y la entenada, o la suegra y el yerno, existiendo numerosos defensores tanto de la respuesta afirmativa como negativa. En la práctica los papas constantemente se habían negado a dispensar en ese grado. En los restantes grados de la línea recta y en los de la línea colateral, se convenía generalmente que el impedimento era de derecho eclesiástico.

La afinidad lícita fue conservada en el Código de 1917, si bien la disciplina ante codicial fue profundamente reformada, porque, a partir del Código, la afinidad sólo tuvo su origen en el matrimonio válido, estuviese o no consumado, y dirimía el matrimonio en cualquier grado de la línea recta y hasta el segundo grado en la línea colateral computado, siempre, al modo canónico (c.1077 § 1). ${ }^{42}$

\section{3. a. 3. Afinidad ilícita}

Era la que se generaba ex copula fornicaria. Originalmente, el impedimento de afinidad surgía sólo del matrimonio válido, pero, a partir del siglo IX, el origen de este impedimento se situó en la cópula o, por lo menos, la cópula ilícita fue también considerada causal de este impedimento que en el Concilio de Trento (1545-1563) ${ }^{43}$ quedó reducido al primer y segundo grado de afinidad. Los grados de afinidad correspondían a los de consanguinidad y se computaban del modo canónico, por

41 El Código de Derecho Canónico de 1983 dio un paso más al reducir el impedimento hasta el cuarto grado en la línea colateral (c.1091 $\S 2$ ) pero ahora contado según el modo romano (c.108); además, en lo referido a la dispensa del impedimento existente entre tíos(as) y sobrinas(os), no lo dejó reservado a la Santa Sede (c.1078 § 2).

42 El Código de Derecho Canónico de 1983 también dio un paso más en esta materia, al eliminar el impedimento de afinidad en la línea colateral, dejándolo sólo reducido a la línea recta (c.1092).

43 Conc. Trid., sess. 24 de ref. mat. c. 4. lo que, por ejemplo, Pedro, que había conocido carnalmente a Francisca era afín con la madre e hija de ella, en primer grado de línea recta, y con la abuela y nieta en segundo grado de la misma línea; con la hermana de ella, en primer grado de la línea colateral; y con la prima hermana, tía o sobrina, en segundo grado. A veces, la afinidad ex copula illicita sobrevenía al matrimonio ya contraído, esto es, cuando el trato carnal tenía lugar con los consanguíneos del consorte en primer o segundo grado. En estos casos el matrimonio no se disolvía, pero privaba al delincuente, como se decía en los textos de la época, del derecho a exigir el débito conyugal, de manera que si lo pedía, pecaba gravemente; en cambio no perdía ese derecho el cónyuge que ignoraba el hecho.

El Código de Derecho Canónico decidió conservar el impedimento dirimente de afinidad, pero restringido sólo a la afinidad lícita, eliminando la afinidad ilícita.

\section{3. b. Parentesco espiritual}

En cuanto al impedimento proveniente de parentesco espiritual tampoco la posición del arzobispo era clara en cuanto a conservarlo o rechazarlo, pues si bien ofrece algunas razones que apuntan a entender que se opone a su eliminación o reducción, no expresa con claridad su postura. Entendía que "si la razón del mismo es la reverencia a la recepción del sacramento, mucha utilidad debe verse para reducir el mismo". Citando al Decreto de Graciano, ${ }^{44}$ entendía que la "regeneración del Espíritu Santo por el celeste sacramento" vinculaba sólo al bautizante con el bautizado, y al confirmante con el confirmado. "De esta manera, reverencia debe suponer ciertamente en el varón bautizado toda mujer que, en caso de necesidad, purifica al mismo con el agua de la regeneración". Y en el caso del laico bautizante "permanece, sin embargo, la reverencia al carácter sacramental del bautismo de cuya colación el mismo fue instrumento y porque tiene alguna repugnancia con la materia matrimonial". Sin perjuicio de lo anterior, el arzobispo no percibía "ninguna causa especial de reverencia entre el bautizante o encargado y los padres del bautizado o receptor; mucho menos tal reverencia que haga oposición a las obligaciones conyugales".

Vinculado a este impedimento estaba el tema de la compaternidad espiritual, "que, por una parte, es verdaderamente espiritual, por otra natural", tema al que también el arzobispo dedicó unas líneas. Entendía el prelado que no se veía óbice "para contraer, disuelto el primer vínculo, otra compaternidad, a saber la común paternidad de los futuros hijos, natural e igualmente espiritual como fluye del matrimonio cristiano. Así los fieles quizá se retraerán menos del oficio de encargado, y se presentaría más expedito el estado conyugal como una vía para todos".

La relación de parentesco espiritual fue más antigua que el impedimento, el que fue introduciéndose, como sucedió con otros impedimentos, por la costumbre y por algunas disposiciones legislativas particulares, hasta que alcanzó carácter universal. De hecho, en las Decretales (1234) se resuelven algunas dudas que suponen la vigencia del impedimento, el que suscitaba problemas por la variedad de situaciones que lo configuraban, agravados por la

\footnotetext{
44 C. 30 q. 3 c. 1.
} 
multiplicidad de padrinos. El Concilio de Trento ${ }^{45}$ fijó en dos el número de padrinos y redujo la figura del impedimento a la paternidad espiritual, esto es, quedaba prohibido el matrimonio entre bautizante y bautizado y entre padrino y bautizado, y a la compaternidad, o sea, entre los padres del bautizado y el bautizante y padrinos. ${ }^{46}$

Donoso ${ }^{47}$ autor de unas Instituciones de derecho canónico muy difundidas en América Latina en la segunda mitad del siglo XIX y los primeros años del siglo Xx hasta la codificación, explicaba que se trataba de un impedimento de derecho eclesiástico y, por lo mismo, dispensable, y que dirimía el matrimonio en las siguientes situaciones: i) entre el bautizante y bautizado y padre y madre de éste; ii) entre los padrinos y el bautizado, el padre y madre del mismo; iii) entre el confirmante y el padrino o madrina de confirmación, por una parte, y entre el confirmante con el confirmado, su padre o su madre, por la otra. En el sentir común, este impedimento comprendía también al que, en caso de necesidad, confería el bautismo privado, aceptándose, empero, algunas excepciones. ${ }^{48}$ En el Concilio Vaticano I (1860-1870) se había sugerido modificar este impedimento restringiéndolo al bautizado y padrinos y derogando lo referido al sacramento de la confirmación. ${ }^{49} \mathrm{El}$ arzobispo de Guatemala en su poco explícito postulatum parecía excluir el impedimento para el confirmante y confirmado. De hecho, Klumper no lo recogió en su resumen de los postulata, no obstante que hubo algunos prelados que expresamente pidieron que el impedimento no se extendiese al sacramento de la confirmación.

El Código de Derecho Canónico no eliminó el impedimento, pero, recogiendo lo que ya se había sugerido en el Concilio Vaticano I, lo limitó al establecer que "solamente el bautizante y el padrino contraen por el bautismo parentesco espiritual con el bautizado" (cc.768, 1079). Se trataba, además, de un impedimento de grado menor, por lo que la dispensa del mismo se concedía con facilidad. ${ }^{50}$ Se eliminó, así, el impedimento con ocasión del sacramento de la confirmación y se eliminó también la compaternidad, materias en las que se puede decir que el prelado fue escuchado.

45 Conc. Trid., sess. 24 de ref. mat. c. 2.

46 Alonso Lobo, A., o.p.; Miguelez Domínguez, L.; Alonso Morán, S., o.p. 1963. Comentarios al Código de Derecho Canónico, II: 596-597. Madrid: Biblioteca de Autores Cristianos.

47 Donoso, J. 1848-1849. Instituciones de derecho canónico americano, II: 150. Valparaíso: Imprenta El Mercurio. Hubo nuevas ediciones en Paris 1854, Santiago 1861, Paris 1868, 1885, Friburgo 1909. En la homilía pronunciada por el obispo de San Luis de Potosí, Ignacio Montes de Oca, en las exequias solemnes celebradas durante el Concilio Plenario de América Latina (1899) por los obispos difuntos, el predicador preguntaba "¿quién de vosotros, Venerables Padres, no ha leído las Instituciones Canónicas, con gran trabajo escritas por el preclaro obispo de La Serena, Justo Donoso?". Pontificia Commissio pro America Latina. 1999. Acta et decreta Concilii Plenarii Americae Latinae in Urbe celebrati anno Domini MDCCCXCIX, ed. facsimilar: cxvi. Ciudad del Vaticano: Libreria Editrice Vaticana.

48 Donoso, J. 1848-1849: II, 23-24.

49 Conte a Coronata, M., ofm. Cap. 1957. Institutiones iuris canonici ad usum utriusque clero et scholarum. De sacramentis tractatus canonicus, III: De matrimonio et de sacramentalibus: 558. Torino.

50 De Salazar Abrisquieta, J. 1977. “Capacidad e impedimentos matrimoniales", en Catedráticos de Derecho Canónico de Universidades Españolas, Derecho canónico: 428. Pamplona: Eunsa. Hubo que esperar hasta el Código de Derecho Canónico de 1983 para que se eliminase el impedimento de parentesco espiritual.

\section{3. c. Parentesco legal}

Las últimas ideas en torno a los impedimentos las dedicó el arzobispo al impedimento de parentesco legal, respecto del cual, a diferencia de lo sucedido con sus postulata anteriores, fue enfático en sugerir que se suprimiera. Según él, "muy raramente en algún lugar, si no me engaño, existe la adopción"; se trataba, por lo demás, de una institución ficticia con la que los romanos habían buscado imitar demasiado la naturaleza y el arzobispo era derechamente contrario a ella "porque la necesaria residencia ordinaria bajo el mismo techo de los hijos adoptivos y los naturales de un mismo padre ofrecería muchísimo peligro, al menos ocasión de incontinencia". Es por lo que sugería derechamente su supresión.

La adopción es una institución meramente civil que tiene su origen en el derecho romano en el que alcanzó un notable desarrollo. ${ }^{51}$ La adopción generaba un vínculo estrecho, si bien jurídico, entre el adoptado y los miembros naturales de la familia del adoptante lo que hizo que los romanos establecieran prohibiciones para los matrimonios entre unos y otros. ${ }^{52}$ La Iglesia aceptó en su propio fuero la legislación romana del impedimento de parentesco legal desde antes del siglo XIII, canonizando dicha legislación, esto es, haciendo canónica la legislación civil. A tenor de esta canonización, la adopción hecha según las normas de la legislación civil de cada país, si ella concordaba sustancialmente con la adopción romana, producía las mismas prohibiciones que ésta; en otras palabras, lo que se precisaba averiguar en cada caso era la conformidad sustancial entre la legislación de cada país con el derecho romano: si dicha conformidad se producía, los impedimentos canónicos eran no los establecidos en la legislación de que se tratase, sino los del derecho romano. De esta manera, la dificultad estribaba en juzgar si la legislación del país acerca de la adopción convenía sustancialmente con la adopción romana. Esta era la disciplina vigente al momento de la codificación.

En lo que a la América Hispana se refiere, la adopción estaba regulada en las Siete Partidas, texto del rey Alfonso $X$ el sabio escrito en el siglo XIII que había regido esta materia durante todo el período indiano y que había seguido vigente después de la independencia. ${ }^{53}$ En él se había recogido sustancialmente la disciplina del derecho romano y, como explicaba Donoso, ${ }^{54}$ existía el impedimento: i) entre el adoptante y el adoptado perpetuamente; ii) entre el adoptado y los hijos naturales (= biológicos) del adoptante mientras dura la adopción, o sea, mientras la persona adoptada no es emancipada; iii) entre el adoptante y la mujer del adoptado, y entre éste y la mujer de aquél, siendo este impedimento perpetuo como el primero.

No fue el arzobispo de Guatemala el único en solicitar la derogación de este impedimento, pues junto a él estuvieron los obispos chilenos ${ }^{55}$ y los de numerosas otras

51 Guzmán Brito, A. 1997. Derecho privado romano: I, 360-363. Santiago de Chile: Editorial Jurídica de Chile.

52 Ibídem: 338-340.

53 Guzmán Brito, A. 2000: 179-189.

54 Donoso, J. 1848-1849: II, 159. Dougnac Rodríguez, A. 2003. Esquema del derecho de familia indiana: 462-480. Santiago de Chile: Instituto de Historia del Derecho Juan de Solórzano Pereyra.

55 Salinas Araneda, C. 2008. "El primer aporte de los obispos chilenos a la codificación del derecho canónico de 1917: los postulata episcoporum acerca del matrimonio". Historia 41: 429-431. 
provincias eclesiásticas. ${ }^{56}$ El Código de Derecho Canónico, sin embargo, no derogó este impedimento dirimente sino que lo conservó, si bien simplificando notablemente la disciplina, canonizando la ley civil de cada país: "los que por la ley civil son inhábiles para contraer entre sí matrimonio a causa del parentesco legal que nace de la adopción, por prescripción del derecho canónico no pueden casarse entre sí válidamente" (c.1080). ${ }^{57}$ La propuesta del arzobispo, así, no fue escuchada.

\section{Acerca de la usura}

En el último apartado de sus postulata, el arzobispo abordaba un tema del todo diferente: la usura. Y lo hacía bajo la forma de preguntas que fueron abordando temas de la actualidad económica, en especial referidos a la posibilidad de ganar intereses con el dinero, para concluir solicitando que se incorporase en el nuevo Código una tipificación más precisa del delito de usura, del que proponía un concepto.

La primera pregunta se hacía a partir del Evangelio de Lucas $6,35^{58}$ de donde, junto a otros lugares de la Sagrada Escritura que no especificaba, proponía que se considerase si acaso no se había de entender que todo interés por préstamo de dinero estaba prohibido por derecho divino. A la anterior seguía inmediatamente otra pregunta según la cuál, supuesto que la usura estaba condenada en las Sagradas Escrituras, acaso no habría que entender como de

56 Los padres de la provincia de Poznan (Polonia), de la provincia de París (Francia), de Holanda, de España, de la provincia de Burgos (España), el arzobispo de Bamberg (Alemania), el patriarca de Lisboa (Portugal), el obispo de Montauban (Francia), los padres de la provincia de Montreal (Canadá), de la provincia de Besançon (Francia), de la provincia de Halifax (Canadá), de la provincia de Lyon (Francia), el obispo de Tulle (Francia), los padres de la provincia de Michoacán (México), los obispos de Irlanda, Postulata: 177. Algunos, en concreto los padres de la provincia de Albi (Italia), ibídem: 170, si bien no sugerían la derogación de este impedimento, pedían que al menos se indicasen los casos en que se contraía; otros, como el arzobispo de Baltimore (USA), el obispo de Ogdensburgo (USA) y el obispo de Irenton, ibídem: 169, sugerían examinar primero la posibilidad de posponer los cánones acerca del parentesco legal y quizá, derogarlos. Y si no se podía abrogar, que se determinaran cuidadosamente las condiciones requeridas para que se produjera la adopción, como lo sugerían los padres de la provincia de Bélgica, ibídem: 172; algunos, como el obispo de Würzburg (Alemania) y los padres de la provincia de Leopolis (Ucrania), ibídem: 167; y los padres de la provincia de Salzburgo, ibídem: 173, en cambio, postulaban que el impedimento se limitase sólo al adoptante y adoptado; o se limitase al máximo, como sugerían el obispo de Kingston en Canadá y los padres de la provincia de Munich (Alemania), ibídem: 169; o que fuese un mero impedimento impediente, según el obispo de San Alberto en Canadá, y el obispo de Londres en Canadá, ibídem: 168; o que fuese necesario que la adopción se hubiese hecho conforme a las leyes del Estado y el adoptado hubiese pasado a la familia y potestad del adoptante, como era la propuesta de los padres de la provincia de Tarragona (España), ibídem: 170.

57 El Código de Derecho Canónico de 1983 conservó también este impedimento, pero a diferencia del Código de 1917, definió los grados en que dicho impedimento se produce: no pueden contraer válidamente matrimonio entre sí quienes están unidos por parentesco legal proveniente de la adopción, en línea recta y en segundo grado de línea colateral (c.1094), contados, ahora, al modo romano.

58 Lc 6, 35: "Más bien, amad a vuestros enemigos; haced el bien, y prestad sin esperar nada a cambio; y vuestra recompensa será grande, y seréis hijos del Altísimo, porque él es bueno con los ingratos y los perversos". una misma entidad moral la usura y el mutuo con interés. Y a propósito de esto último, la siguiente pregunta se planteaba si acaso el derecho natural prohibía aceptar algo de dinero en dominio sobre capital puesto a ganancias con mutuario que pagase libremente y por propia voluntad, excluido todo dolo y coacción. Y todavía preguntaba, sobre la base de que la usura, largamente distante de la judía, estaba prohibida por derecho natural y divino, si acaso podría la Iglesia consentir y aprobar el permiso hecho por los gobiernos católicos de recibir algo sobre el capital puesto a ganancias.

Supuestas las preguntas anteriores, referidas a la usura y al mutuo, el prelado planteaba seguidamente una situación diferente: referido al dominio de los gobiernos, declarado eminente, el prelado se preguntaba si acaso sería verdadero dominio, como verdadero derecho privado de dominio eficaz en sus cosas, o más bien, como parecía manifiesto, solo era una suprema administración, que permitía el despojo de las cosas privadas o, como se decía ahora, una expropiación por utilidad pública, siendo el dueño compensado exactamente con el justo precio. $Y$ acto seguido se preguntaba si acaso hubiese podido la Iglesia aprobar la aceptación de intereses con un título de la ley civil no concurrente.

A la luz de estas reflexiones expuestas en forma de preguntas, terminaba el prelado preguntándose si no sería conveniente establecer en la ley canónica una noción más legítima del delito de usura, proponiendo él mismo la siguiente definición: "delito por el cual alguien que abusa de la ignorancia de otro o de su necesidad le exige mayores intereses de dinero que la ley o la costumbre permite".

El tema de la usura y de los intereses dinerarios ha sido una materia que ha estado presente desde los primeros siglos en la reflexión de la Iglesia. Cuando surgió el cristianismo y se extendió, lo hizo en el seno de una cultura en la que la usura era uno de los medios de comercio y de enriquecerse. Pero la usura era uno de los pecados más fustigados por el Antiguo Testamento, el que extendía su condena también al préstamo con interés. En este ambiente, los Padres de la Iglesia enseñaron la doctrina bíblica, atacando duramente a quienes se enriquecían con préstamos a interés, pues la usura, según expresiones patrísticas, era "una cría de víboras", "prueba de una gran vileza", "una inhumanidad", algo en sí "detestable, odioso y execrable", "engañosa y fraudulenta", que entrañaba "dureza de corazón". 59 San Basilio explicaba así la razón de esta condena: "a la verdad, es extremo de inhumanidad que uno tenga que pedir prestado por faltarle lo más necesario para sostener la vida, y el otro no se contente con el capital, sino que se proponga hacer negocio y aumentar su opulencia a costa de las calamidades de los pobres"..$^{60}$ Los Padres de la Iglesia eran testigos de las injusticias provocadas por la usura, por lo que hacían ver a los cristianos de su tiempo que prestasen sin interés, porque, en definitiva, como escribía el mismo san Basilio, salían ganando el que prestaba y el que recibía el préstamo sin interés: "da el dinero que te sobre, no gravándolo con rédito, y a los dos os irá bien. Tu tendrás tus bienes seguros; el otro que los ha recibido, sacará provecho de su uso". 61

59 Fernández, A. 1965. Compendio de teología moral: 515. Madrid.

60 Homilia II in Ps. 1, idem.

61 Homilia II in Ps. 5, idem. 
La condena de todo préstamo con interés pasó a la tradición posterior, pero el desarrollo económico que se inició a partir del siglo Xv hizo que la industria y el comercio dieran lugar a nuevas fuentes de riquezas haciendo cambiar la función del dinero, por lo que la moral católica admitió lentamente la licitud moral de los préstamos con interés. Además, "la fluidez del dinero cambiaba la naturaleza de los préstamos que se hacían en otras épocas, cuando el interés exigido podía despojar de la propiedad en el caso de que no fuese posible el pago de la deuda". ${ }^{62}$ Esta tarea correspondió principalmente a los grandes teólogos españoles del siglo XVI -los magni hispani- quienes, desde las universidades de Salamanca y Alcalá, desarrollaron su magisterio teológico, particularmente en el campo de la moral social, económica y política, a través de sus tratados De iustitia et iure. Haciendo finos análisis estos teólogos distinguieron entre "usura", "lucro" y "préstamos con interés", condenando la usura y el lucro exagerado, pero afirmando la licitud de que se cobrase un interés por el dinero prestado. Al final de la época, cuando las operaciones de comercio y de cambio eran no sólo frecuentes, sino de grandes volúmenes, se permitió cobrar intereses en situaciones normales, pero teniendo claro que "si la recompensa excede de la justa estimación, se presume usura". ${ }^{63}$

Ya en pleno siglo XVIII, el 1 de noviembre de 1745, el Papa Benedicto XIV (1740-1758) publicó la carta encíclica Vix pervenit, acerca de la moralidad de los préstamos con interés. ${ }^{64}$ Y en una instrucción del año 1873, la Sagrada Congregación de Propaganda Fide, ${ }^{65}$ después de sentar: i) que no se puede exigir nada por razón del contrato mismo de préstamo; ii) pero sí puede exigirse por título extrínseco, añadía que, aun cuando faltasen otros títulos, como podían ser el lucro

\footnotetext{
62 Fernández, A. 1965: 545.
}

63 Ibídem: 546, citando a Lessio. La literatura sobre usura es abundante, por lo que no es posible recogerla en una simple nota. Me limito a citar algunos títulos más recientes: Barile, N. L. 2008. “I debatito sul prestito a interesse negli ultimi trent'anni tra probabilisti e rigoristi. Un bilancio storiografico". Nuova Rivista Storica 92: 835-874; Bazzichi, O. 2008. Dall'usura al giusto. L'etica economica della Scuola francescana. Torino: Effatà Editrice; Gamba, C. 2004. Licita usura. Giuristi e moralisti tra Medioevo ed età moderna. Roma: Viella Editore; Gamba, C. 2004. "Natura ed usura, La disputa ottocentesca sulla liccità del préstito ad interese". Rivista di Storia del Diritto Italiano 78: 139-186; Munro, J.H. 2003. "The Medieval Origins of the Finantial Revolution: Usury, "Rentes» and Negotiability". The International History Review 25: 505-576; Tan, E.S. 2005. "Origins and Evolution of the Medieval Church's Usury Laws: Economic Self-Interestor Systematic Theology?". The Journal of European Economic History 34: 263-281; Tedeschini, G. 2002. I mercanti e il tempo. La società cristiana e il circolo virtuoso della ricchezza fra Medioevo et Età Moderna. Bologna: II Mulino; Tedeschini, G. 2004. Ricchezza francescana. Dalla povertà volontaria alla società di mercato. Bologna: II Mulino. Además puede verse Gamba, C. 1997. "Natura, propietà ed usura secondo el ius commune", en Atti del Seminario di studi su diritto alla vita e debito estero (S. Agata dei Goti: 1-2 agosto 1996): 99-128. Napoli: Edizioni Scientifiche Italiane; Viglione, A. 1995. "L'usura secondo Jacques Le Goff", en Educare all'uso responsabile del denaro. La comunità cristiana di fronte al fenómeno dell'usura: 278-281. Roma: Dehoniane. Una aproximación más general, a partir de la historia normativa contractual castellana, es la de Álvarez Cora, E. 2005. La teoría de los contratos en Castilla (siglos XVI-XVIII). Madrid: Colegio Nacional de Registradores Propiedad y Mercantiles.

64 Benedicto XIV, carta encíclica Vix pervenit, de 1 de noviembre de 1745, Fontes: I, 939-943.

65 Fontes: VII, n. 4880. cesante, el daño emergente y el peligro de perder el capital o de tener que asumir trabajos insólitos para recuperarlo, se podía dar por suficiente en la práctica el título de la ley civil.

El Código de Derecho Canónico abordó el tema en dos cánones diversos: el canon $1543,{ }^{66}$ al tratar del contrato de préstamo; y el canon 2354, ${ }^{67}$ al condenar el delito de usura. El primero de ellos reprodujo la doctrina tradicional, dejando sentadas las mismas dos prescripciones que se recogían en la instrucción de $1873,{ }^{68}$ es decir: i) que no se podía exigir nada por razón del contrato mismo de préstamo; ii) pero sí podía exigirse por título extrínseco, entendiéndose por estos la ley civil y otros títulos extraños a dicho contrato. El interés legal, empero, tenía una limitación de tipo moral: siempre que no constase que fuese excesivo. Los otros títulos tenían un carácter supletorio, para exigir un interés más alto que el legal. Esta disciplina no significó que la usura dejara de ser un grave delito, pero puso de manifiesto que, debido a la evolución de esta materia, la apreciación del concepto de usura había cambiado. ${ }^{69}$

Con todo, no se acogió la sugerencia del prelado de Guatemala en orden a dar un concepto de usura, pues, si bien la usura era castigada con penas graves, tratándose de laicos el canon tan sólo se hacía eco de la condena hecha en sede estatal, a cuyo ordenamiento correspondía tipificar el delito. En el caso de los clérigos, supuesto que gozaban del privilegio del fuero, debían ser sancionados por tribunales eclesiásticos, pero para esta situación el Código no tipificó el delito, tan sólo dio por sentada su existencia. Si el clérigo no gozaba de tal privilegio, el canon suponía que había sido castigado por la ley estatal que era la que debía tipificarlo.

\section{LOS POSTULATA DEL OBISPO DE NicARAGUA}

Sabemos que, nada más llegar a manos del arzobispo de Guatemala el motu proprio Arduum sane munus de Pío X y la carta circular Pergratum mihi del cardenal Secretario de Estado, los hizo llegar a sus sufragáneos, dos de los cuales se excusaron de participar. Los otros dos, uno de ellos, el obispo de Nicaragua, había comprometido su respuesta, pero la tardanza de la misma hizo que el arzobispo decidiera

66 Código de Derecho Canónico, 1917, can. 1543: "Si se entrega a alguien una cosa fungible, de tal suerte que pase a ser suya y después tenga que devolver otro tanto del mismo género, no se puede percibir ninguna ganancia por razón del mismo contrato; pero al prestar una cosa fungible, no es de suyo ilícito estipular el interés legal, siempre que no conste que es excesivo, y aun uno más alto, si hay título justo y proporcionado que lo cohoneste".

67 Se condena el delito de usura conjuntamente con otros delitos. Código de Derecho Canónico, 1917, can. 2354: § 1. Al seglar que hubiere sido legítimamente condenado por el delito [...] de usura [...] se le ha de considerar excluido por el derecho mismo de los actos legítimos eclesiásticos y de cualquier cargo que pueda tener en la Iglesia, quedando en pie la obligación de reparar daños. § 2. Pero si fuere clérigo el que ha cometido alguno de los delitos consignados en el § 1, debe ser castigado por el tribunal eclesiástico, según la diversa gravedad de la culpa, con penitencias, censuras, privación de oficio y beneficio y de dignidad, y, si el caso lo pide, hasta con la deposición [...]".

68 Esta instrucción aparece mencionada entre las fuentes de este canon junto con la carta encíclica Vix pervenit de Benedicto XIV, en la edición oficial del Código de Derecho Canónico en la que se incluyen las fuentes de cada canon.

69 García Barberena, T. 1964. Comentarios al Código de Derecho Canónico: IV, 514-516. Madrid: Biblioteca de Autores Cristianos. 
enviar sus propias sugerencias sin esperar las demás. Las propuestas del obispo de Nicaragua llegaron a poder del arzobispo cuando ya había enviado las suyas, por lo que, sin más, las despachó a Roma.

Los postulata del obispo de Nicaragua se encuentran escritos en latín, en escritura caligráfica, en un folio y medio, que no lleva ni firma ni fecha; tan sólo el título "De Nicaragua" que se sitúa al comienzo del mismo, después de la frase, escrita en letra de menor tamaño en la parte superior derecha de la primera hoja, De Ecclesiae legibus in unum redigendis, palabras con las que se individualiza el motu proprio de Pío X. Se trató de cinco sugerencias que analizo en el mismo orden en que fueron expuestas por el prelado.

\section{Posibilidad de delegar en sacerdotes para que adminis- tren el sacramento de la confirmación cuando el obispo no puede hacerlo}

La primera de las propuestas del prelado dice relación con el sacramento de la confirmación, y sugería que los obispos pudieren delegar en uno u otro sacerdote para que administraren el sacramento de la confirmación cuando, por causa de una enfermedad o por las distancias de los lugares, el prelado no hubiese podido hacerlo. No fue el único prelado en formular esta sugerencia, pues, junto a él, también la hicieron los padres de la región de Campania (Italia). ${ }^{70}$

Justo Donoso ${ }^{71}$ explicaba que sólo el obispo era ministro ordinario del sacramento de la confirmación según lo había definido el Concilio de Trento $^{72}$ (1545-1563), pero que podía haber un ministro extraordinario pues el Papa podía delegar esta facultad en un simple presbítero, como lo probaba la práctica diaria de la Santa Sede de cometer esta facultad a los presbíteros misioneros que se enviaban o ejercían su ministerio en regiones remotas. "Esta delegación no puede, empero, hacerla el obispo", afirmación que reforzaba con una cita de Benedicto XIV ${ }^{73}$ que declaraba nula la confirmación hecha por un presbítero por la sola delegación de un obispo porque, por derecho, tal delegación estaba reservada a la Sede Apostólica.

El Código de Derecho Canónico conservó la misma disciplina, afirmando en el canon $782 \S 1$ que "Solamente el obispo es ministro ordinario de la confirmación", para agregar en el parágrafo inmediatamente siguiente que "Es ministro extraordinario el presbítero a quien por derecho común o por indulto peculiar de la Sede Apostólica le haya sido concedida esta facultad". Pero, aprovechando la oportunidad de la codificación, el Papa concedió autorización de una vez para siempre, en orden a la válida administración del sacramento a los siguientes presbíteros que, sin estar consagrados obispos, ofrecían la máxima garantía de un ministerio digno y provechoso: los cardenales, ${ }^{74}$ los abades y prelados nullius, los vicarios y prefectos apostólicos (§ 3).

\section{Postulata: 108.}

71 Donoso, J. 1848-1849: II, 37-38.

72 Conc. Trid., sess. 7, De confirmatione, c. 3: "Si alguno dijere que el obispo no es el único ministro ordinario de la confirmación, sino que lo es también cualquier simple sacerdote, sea excomulgado".

73 Benedicto XIV, De sinodo diocesana, lib. 7, cap. $7 \mathrm{n}^{\circ} 7$, cit. por Donoso, J. 1848-1849: II, 38.

74 Este privilegio pontificio dejó de tener razón de ser cuando Juan XXIII (1958-1963) dispuso que en adelante todos los cardenales
La Santa Sede se mostró siempre muy rigurosa y comedida en conceder delegaciones a los presbíteros latinos ${ }^{75}$ para administrar este sacramento, pero con ocasión de la Segunda Guerra Mundial (1939-1945) en la que muchos fieles murieron sin haber sido confirmados, tanto en el frente como en la retaguardia, por falta de ministros capacitados para conferirla, el Papa morigeró el rigor de la antigua disciplina, considerando, además, que las circunstancias por las que empezaba a discurrir el actuar de la Iglesia, sería más difícil a los obispos atender personalmente la administración de este sacramento a sus fieles. El 14 de septiembre de 1946, el Papa Pío XII (1939-1958), mediante el decreto Spiritus Sancti munera, ${ }^{76}$ amplió el número de ministros extraordinarios, estableciendo que podían serlo: i) los párrocos que gozaban de territorio propio; ii) los vicarios parroquiales que gozaban de plena potestad parroquial, pero solos el actual y el ecónomo; y iii) los sacerdotes a quienes de una manera exclusiva y estable les había sido encomendada la plena cura de almas con todos los derechos y deberes de los párrocos, en un territorio determinado y con iglesia determinada. Este decreto supuso la ampliación del número de los ministros extraordinarios de la confirmación, pero hubo que esperar al Código de 1983 para que, finalmente, la sugerencia del obispo de Nicaragua fuera acogida, pues en el canon $884 \S 1$ del Código en actual vigencia se dispuso que "el obispo diocesano debe administrar por sí mismo la confirmación, o cuidar de que la administre otro obispo; pero si la necesidad lo requiere, puede conceder facultad a uno o a varios presbiteros determinados, para que administren este sacramento". La sugerencia del prelado nicaragüense hecha en el lejano 1904, se mostró así, profética.

\section{Nombramiento de vicario capitular por el obispo antes de morir}

La segunda sugerencia del obispo de Nicaragua era que los obispos, si preveían que, por intervención de la autoridad civil, el capítulo catedralicio habría de elegir para vicario capitular a un clérigo mínimamente congruente con la Iglesia, pudieren ellos mismos nombrarlo, antes de morir, así como concedía la Santa Sede por privilegio. Fue la única propuesta hecha en este sentido en esta etapa de la codificación. ${ }^{77}$

Según Donoso, ${ }^{78}$ era principio inconcuso en el derecho que "en todo caso en que cesa o se impide y suspende la jurisdicción del obispo, por cualquier causa canónica, se devuelve ésta al cabildo de su iglesia". Es por lo que el Concilio de Trento $^{79}$ había dispuesto que, después de la

recibieren la consagración episcopal, por lo que pasaron a ser ministros ordinarios del sacramento. Cf. Juan XXIII, Motu proprio Cum gravissima, de 15 de abril de 1962. 1962. Acta Apostolicae Sedis 54: 256-258.

75 Los presbíteros de la Iglesia Griega, sin excepción, administran el sacramento de la confirmación desde tiempo inmemorial, costumbre que ha sido aprobada por la Iglesia latina al declarar válido el sacramento administrado por ellos. Donoso, J. 1848-1849: II, 38.

76 Acta Apostolicae Sedis 38, 1946: 349-358.

77 Postulata: 71-74.

78 Donoso, J. 1848-1849: I, 233.

79 Conc. Trid., sess. 24 de ref. c. 16. 
muerte del obispo, debía el cabildo catedralicio nombrar un vicario capitular dentro de ocho días después de la muerte del obispo, de manera que si no lo hacía, el nombramiento correspondía al metropolitano; y si el fallecido era el metropolitano, el nombramiento correspondía al obispo sufragáneo más antiguo. Era la disciplina vigente al momento del inicio de la codificación.

El Código dispuso en el canon 429 que en caso de sede impedida por el cautiverio, relegación, destierro o incapacidad del obispo, de suerte que ni aun por carta pudiese éste comunicar con sus diocesanos, si la Santa Sede no tomaba otra determinación, el gobierno de la diócesis quedaba en manos del vicario general del obispo o de otros eclesiásticos en quien el obispo hubiese delegado (§ 1). En semejantes casos, el obispo podía, con causa grave, nombrar varios delegados que mutuamente se sucedieren en el cargo (§ 2). Si faltaban todos los anteriores, correspondía al cabildo catedral nombrar un vicario que asumiera el gobierno de la diócesis con autoridad de vicario capitular (§3).

En cambio, en caso de sede vacante por muerte del obispo, por renuncia aceptada por el Romano Pontífice, por traslado o por privación intimada al obispo (c.430 § 1), si no había administrador apostólico o la Santa Sede no había dispuesto lo contrario, pasaba el gobierno de la diócesis al cabildo catedralicio (c.431 § 1) el que, dentro de los ocho días, a contar desde la fecha en que había recibido la noticia de hallarse vacante la sede, debía constituir un vicario capitular que gobernase la diócesis en lugar del cabildo (c.432 § 1).

En otras palabras, la propuesta del obispo de Nicaragua de que, en caso de muerte prevista, pudiese el obispo designar con anterioridad a quien iba a gobernar la diócesis en sede vacante, para el evento de que se temiese la intervención de los gobiernos civiles en el nombramiento de un vicario capitular más afín con los intereses de dichos gobiernos, no pocas veces hostiles a la Iglesia, que a los de la propia Iglesia, no fue acogida. Dicha posibilidad, en cambio, se regulaba para el evento de sede impedida, pero no era ésta la hipótesis en que se colocaba el prelado.

\section{Supresión del derecho de patronato}

La tercera de las propuestas del obispo de Nicaragua se refería al derecho de patronato. Según el prelado, el derecho de patronato, cualquiera que fuese su origen, y particularmente el laical, debía ser completamente abolido, pues la experiencia enseñaba los males que desde él habían venido a la Iglesia. Fue el único obispo que se manifestó en estos términos, si bien los obispos de Chile sugirieron que se rescindiese el derecho de patronato, salvo los derechos adquiridos y aquellos que la Santa Sede se dignara conceder a algunos gobiernos, el que sólo debía consistir en la facultad de presentar personas dignas a obtener un oficio eclesiástico; ${ }^{80}$ otros episcopados hicieron sugerencias en orden a restringir el derecho de adquirir patronatos laicales y reformar las leyes sobre patronato, ${ }^{81} \mathrm{o}$ a no conceder

\footnotetext{
80 Postulata: 39.

81 Los padres de la provincia de Lvov (Ucrania), ídem.
}

nuevos derechos perpetuos de patronato a futuro, ${ }^{82}$ o que se limitara a una o a dos generaciones. ${ }^{83}$

El derecho de patronato era el conjunto de facultades, con algunas obligaciones, que tenía el patrono, esto es, el titular de dicho derecho, en la iglesia o beneficio de que era patrono. La principal de las facultades era la de elegir, presentar o aprobar a la persona a la que se había de conferir el beneficio eclesiástico vacante, y fue tan importante que llegó a definir el derecho de patronato, al punto que en torno a ella giraban casi todos los capítulos del título De iure patronatus de las Decretales. ${ }^{84}$ No necesariamente se confundían presentación y patronato, ya que podía darse la primera sin el segundo y viceversa, pero preciso es reconocer que, al correr de los siglos, el patronato se habría de configurar fundamentalmente como un derecho de presentación para cubrir cargos eclesiásticos, de manera que la presentación correspondía al poder político investido del derecho patronal, en tanto que el nombramiento correspondía a la autoridad eclesial.

El derecho de patronato se adquiría por tres capítulos, frecuentemente relacionados entre sí: i) por donación del solar para construir una iglesia; ii) por construir la iglesia; iii) por dotarla. También se adquiría por fundar y dotar un beneficio eclesiástico. Todo esto podía hacerlo cualquier persona quien, por ello, adquiría el derecho de patronato sobre esa iglesia o beneficio. Estas normas del derecho medieval, empero, se referían principalmente a los beneficios simples o menores y no a los obispados, cuya provisión era, en todo caso, de mayor interés para los reyes. De esta manera, el origen del derecho de patronato no era sino la gratitud de la Iglesia hacia sus bienhechores, correspondiendo a los beneficios recibidos con otros que ella bondadosamente concedía para estimularles a realizar dichas fundaciones, con el fin de aumentar el culto divino. ${ }^{85}$

En lo que a América se refiere, tras insistentes peticiones del rey Fernando el Católico (1452-1516), el Papa Julio II (1503-1513), mediante la bula Universalis Ecclesiae Regiminis de 28 de julio de $1508,{ }^{86}$ concedió a los reyes de España el patronato universal de todas las iglesias de las Indias; se trataba de una concesión que no había existido nunca hasta entonces en el derecho canónico y comprendió todas las diócesis y las dignidades eclesiásticas de ellas. Como el más importante de los derechos que concedía el patronato al patrono era el de presentación, el patronato universal concedido a los reyes de España permitió a estos gozar del derecho de que no se nombrase ninguna dignidad eclesiástica en América sin la previa presentación de un candidato idóneo por su parte. El monarca no tenía derecho a nombrarlas él personalmente, pero tenía una gran interven-

82 Los obispos de la región de Campania (Italia), ibídem: 38.

83 Los obispos de España, ídem.

$84 \times 3,38,1-31$.

85 Alonso Morán, A., o.p.; Cabreros de Anta, M., c.m.f. 1964. Comentarios al Código de Derecho Canónico: III, 114-115. Madrid: Biblioteca de Autores Cristianos.

86 Su texto en Metzler, J. (ed.). 1991. America Pontificia. Primi saeculi evangelizationis 1493-1592: 104-107. Città del Vaticano: Libreria Editrice Vaticana. También en Hernáez, F. J. 1895. Colección de bulas, breves y otros documentos relativos a la Iglesia de América y Filipinas: I, 24-25; Bruselas: Imprenta de Alfredo Vromant. De Leturia, P., s.j. 1959. Relaciones entre la Santa Sede e Hispano-América 14931835, I: Época del real patronato 1493-1800: I, 253-258. RomaeCaracas. 
ción en su designación. Desde 1508 hasta la independencia no se proveyó ningún cargo sin la previa presentación real: al rey le correspondía presentar los candidatos a arzobispos, obispos y miembros del cabildo catedralicio; los representantes del rey en América presentaban al obispo los candidatos a párroco para que éste extendiera el nombramiento. De este modo, la carrera de todos los eclesiásticos quedó en gran medida en manos de la Corona. En el ejercicio de este patronato, sin embargo, tanto el rey como sus ministros fueron en la práctica mucho más lejos, dando lugar a abusos de jurisdicción que terminaron por privar a la Iglesia en América de su legítima libertad. ${ }^{87}$

Producida que fue la independencia, los gobiernos republicanos de América Latina se hicieron continuadores del patronato indiano. En ocasiones, las menos, lo obtuvieron por especial concesión de la Santa Sede; en otras, las más, simplemente lo asumieron de hecho, lo que significó que durante el siglo XIX los gobiernos civiles, no siempre afines con la Iglesia, tuvieran un amplio margen de intervención en los asuntos eclesiales. Era a esta situación a la que se refería el obispo de Nicaragua, con especial atención a los patronatos laicales.

El Código de Derecho Canónico no abolió el derecho de patronato, dedicándole todo un capítulo del Libro III, que estaba dedicado a las cosas. ${ }^{88}$ La larga tradición que en

87 Para una bibliografía general sobre el patronato indiano, tanto en la literatura de la época como moderna, se puede ver Salinas Araneda, C. 2015. "La formación de un espacio jurídico transnacional en el siglo XIX a partir del patronato indiano". Rechtsgeschichte, Zeitschrift des Max-Planck-Instituts für europäische Rechtsgeschichte 23: 207-221. Para una visión general del tema, Salinas Araneda, C.2009. "Las relaciones Iglesia-Estado en la América indiana: patronato, vicariato, regalismo", en J. G. Navarro Floria (ed.), Estado, derecho y religión en América Latina: 17-52. Buenos Aires: Marcial Pons; también "Le relazioni Chiesa-Stato in America Latina: introduzione storica", en J. G. Navarro Floria; D. Milani (ed.), Diritto e religione in America Latina: 19-67. Bologna: II Mulino. En los últimos años se han ido produciendo nuevos trabajos, de notable calidad, que están aportando nuevas luces sobre el tema: Albani, B. 2012. "Nuova luce sullere lazioni tra la Sede Apostolica e le Americhe. La pratica della concessione del 'Pase regio' ai documenti pontifici destinati alle Indie", en C. Fernal (ed.), Eusebio Francesco Chini e il suo tempo. Una riflessione storica: 83-102. Trento: Fondazione Bruno Kessler; Albani, B. 2014. “Un nuncio per il Nuovo Mundo. II ruolo della nunciatura di Spagna come istanza di giustizia per i fedeli americani tra Cinque e Seicento", en P. Tusor; M. Sanfilippo (ed.), II papato e le Chiese locale. Studi / The Papacy and the local Churches. Studies: 257-286. Viterbo: Sette Città; Pizzorusso, G. Sanfilippo, M. 1998. "L'attenzione romana alla Chiesa coloniale IspanoAmericana nell'età di Filippo II", en J. Martínez Millán (ed.), Felipe Il (1527-1598). Europa y la monarquía católica: 321-340. Madrid: Parteluz; Sanfilippo, M.; Pizzorusso, G. 2004. “L’America iberica e Roma fra Cinque e Seicento: notizie, documenti, informatori", en M. Sanfilippo; A. Koller; G. Pizzorusso (ed.), Gli archivi della Santa Sede e il mondo Asburgico nella prima Età Moderna: 73-118. Viterbo: Sette Città; Pizzorusso, G. 2014. "Nuovo Mundo cattolico e Papato: Chiesa coloniale, Chiesa missionaria, Chiesa locale (secoli XVI-inizio XIX)", en P. Tusor; M. Sanfilippo (ed.), II papato e le Chiese locale. Studi / The Papacy and the local Churches. Studies: 205-256. Viterbo: Sette Città. Para una aproximación al patronato desde la perspectiva de los obispos españoles, Barrio Gozalo, M. 2004. El real patronato y los obispos españoles del Antiguo Régimen, Madrid: Centro de Estudios Políticos y Constitucionales.

88 Código de Derecho Canónico, 1917, Libro III, De las cosas; Quinta Parte, De los beneficios y otros institutos eclesiásticos no colegiados; Título XXV, De le beneficios eclesiásticos; Capítulo IV, Del derecho de patronato, cánones 1448-1471. esta materia había habido en los siglos anteriores impedía derogar esta vieja institución sin más. Pero esa misma larga experiencia mostraba que el derecho de patronato, en lo referente a la presentación, ocasionaba no pocos ni pequeños inconvenientes, por lo que la Iglesia aprovechó la ocasión de la codificación para abolirlo en absoluto para lo futuro, disponiendo en el canon $1450 \S 1$ que "por ningún título se puede en lo sucesivo constituir válidamente derecho alguno de patronato". Y por lo que se refería a los derechos de patronato ya establecidos, dispuso que los ordinario locales procuraren que los patronos, "en lugar del derecho de patronato de que gozan, o por lo menos en lugar del derecho de presentación, acepten para sí y para los suyos sufragios espirituales aun perpetuos" (c.1451 § 1). Si los patronos se rehusaban, su derecho de patronato se regiría por los cánones que el mismo Código establecía (c.1451 § 2).

La sugerencia del obispo de Nicaragua, a la luz de lo que finalmente reguló el Codex, no estaba alejada de la percepción que tenían los codificadores del problema que presentaba el derecho de patronato en las nuevas realidades que vivía la Iglesia, pues, de hecho, el derecho de patronato fue abolido a futuro en términos absolutos. Bien puede decirse, entonces, que la sugerencia del prelado centroamericano fue acogida por los codificadores.

\section{Cambiar la teoría de los beneficios}

Parecía oportuno, manifestaba el obispo de Nicaragua en su cuarta sugerencia, que se cambiase la teoría de los beneficios, al menos los parroquiales, ya por la dificultad de la perpetuidad, ya por la intervención del gobierno civil. Se trataba de una materia vinculada a la anterior, que el prelado circunscribía particularmente a los beneficios parroquiales. En términos parecidos se manifestó el arzobispo de Nueva Orleans (USA), ${ }^{89}$ quien pedía que todas las leyes referidas a los bienes beneficiales fuesen revisadas y en muchos aspectos cambiadas o simplificadas.

El beneficio era definido por Donoso, ${ }^{90}$ como "derecho perpetuo, instituido por autoridad de la Iglesia, que compete al clérigo, por razón de un oficio espiritual, para percibir, en nombre propio, cierta parte de los frutos de los bienes eclesiásticos". Era, así, el modo definido por la Iglesia para que los clérigos se procurasen su honesta y congrua sustentación con los réditos que percibían. La perpetuidad del mismo, que era una de las dificultades que ponía de relieve el prelado de Nicaragua, era una característica que identificaba al beneficio, al punto que es la idea con la que Donoso empezaba a definirlo: "derecho perpetuo". De esta manera, el derecho estaba perpetuamente anexo al respectivo oficio, por lo que, faltando el titular por su muerte $u$ otra causa legítima, se transmitía a su sucesor; pero mientras dicho beneficiado viviese no podía quitársele, a menos que lo renunciase o se le privase de él por algún delito, en virtud de sentencia judicial.

Cuatro eran los modos de conferirse los beneficios, a saber: elección, postulación, colación e institución. De ellos,

89 Postulata: 223.

90 Donoso, J. 1848-1849: II, 290. 
es este último el que me interesa, porque es al que se refería el prelado cuando lo vinculaba con la intervención de las autoridades civiles, pues la institución no era otra cosa que "la concesión de un beneficio hecha a presentación de aquel que tiene derecho de patronato". ${ }^{91}$ En la América indiana, la provisión de parroquias estaba regulada por la Recopilación de Indias, que, entre otras cosas, disponía ${ }^{92}$ que los prelados debían proponer a la autoridad real correspondiente una terna con los mejores evaluados en el respectivo concurso de oposición que debía haberse llevado a cabo, para que, de entre ellos, el virrey o gobernador presentasen el elegido por ellos al obispo para que éste le diera la colación y canónica institución del beneficio. Producida que fue la independencia, como consecuencia de la continuación del ejercicio del patronato que asumieron las nuevas autoridades, "en Chile y generalmente en las otras repúblicas de Hispano-América, la ejercen, de ordinario, los respectivos presidentes, del propio modo y en la misma forma que los antiguos virreyes y presidentes, con arreglo a la ley 24 , tit. 6, lib. 1 de Indias". ${ }^{93}$

La larga tradición histórica del régimen beneficial que, con el tiempo, se había convertido en el modo por excelencia para la honesta y congrua sustentación de los clérigos, fue acogido en el Código, que le dedicó una particular atención. ${ }^{94}$ No hay que olvidar que la intención de Pío $X$ al iniciar la codificación era conservar la disciplina vigente, introduciéndole, eso sí, las reformas que fueren necesarias, pero no se trataba de crear una nueva institucionalidad. El primero de los nuevos cánones que regularon los beneficios eclesiásticos proporcionó un concepto del mismo en el que, nuevamente, se puso de relieve la nota de perpetuidad a la que aludía el prelado: "El beneficio eclesiástico es una entidad jurídica constituida o erigida a perpetuidad por la competente autoridad eclesiástica, que consta de un oficio sagrado y del derecho a percibir las rentas anejas por la dote al oficio" (c.1409). De esta manera, la revisión que se hizo de la disciplina canónica del beneficio con ocasión de la codificación no significó un cambio en esta característica que continuó definiéndolo, con lo que la sugerencia llegada a Roma desde Nicaragua no fue atendida. Preciso es tener presente, empero, que esta característica esencial de la perpetuidad hay que entenderla de dos maneras diversas: una perpetuidad objetiva, que es a la que se refería el canon, es decir, el beneficio no cesaba con su titular, sino que continuaba para ser conferido a otro. La perpetuidad subjetiva, es decir, la investidura vitalicia del titular, en cambio, no era esencial, aunque ella fuese conveniente e, incluso, deseada por la Iglesia.

El sistema beneficial fue el núcleo fundamental del derecho patrimonial de la Iglesia desde la Edad Media. Sin embargo, a partir del siglo XIX, y acaso, de antes, empezó a arrastrar una crisis cada vez más aguda, debido, en parte, a la desaparición de casi todos los bienes raíces eclesiásticos en que se apoyaba por las leyes desamortizadoras de los

\section{1 bídem: 308.}

92 Rec. Ind. 1. 6. 24.

93 Donoso, J. 1848-1849: I, 245.

94 Código de Derecho Canónico, 1917, Libro III, De las cosas; Quinta Parte, De los beneficios y otros institutos eclesiásticos no colegiados; Título XXV, De los beneficios eclesiásticos; cánones 14091488 , distribuidos en seis capítulos. gobiernos hostiles a la Iglesia, lo que, cuando el obispo de Nicaragua escribía sus postulata, era ya una cruda realidad en América Latina. Es por lo que el Código hizo una revisión de la disciplina respectiva, ampliando, entre otras cosas, el concepto de la dote del beneficio. ${ }^{95}$ Lo anterior, unido al hecho de que el sistema beneficial se oponía a una verdadera solidaridad económica entre las distintas personas jurídicas eclesiásticas, hizo que el Concilio Vaticano II manifestase el deseo de que "sea abandonado o al menos reformado", 96 tarea que asumió la nueva codificación de 1983. Es decir, hubo que esperar hasta la nueva codificación del derecho canónico para que la pretensión del prelado de Nicaragua fuese no sólo acogida, sino que, incluso, superada.

\section{5. de las cosas eclesiásticas cuando urge la necesidad o el peligro de usurpación}

La última de las propuestas llegadas a Roma desde Nicaragua se refería a la enajenación de los bienes eclesiásticos cuando urgía la necesidad o había peligro de usurpación, en cuyo caso sugería el prelado que la enajenación, por derecho propio, pudiese ser acordada por el obispo fuera del consentimiento del cabildo eclesiástico. Fue la única propuesta en este sentido en esta etapa de la codificación.

Explicaba Donoso ${ }^{97}$ que "por enajenación se entiende, propiamente, todo acto por el cual se transfiere en otro el dominio de una cosa. Mas, con respecto a los bienes eclesiásticos, este nombre comprende no sólo la donación, venta y permuta, sino la enfiteusis, el feudo, la locación por más de tres años, el empeño e hipoteca y, en fin, toda transacción o convención en que hay traslación de dominio". Había algunas cosas cuya enajenación estaba prohibida, en concreto: i) los bienes inmuebles, en los que quedaban comprendidos los derechos, acciones, servidumbres, censos o réditos anuales; ii) los muebles preciosos, entendiéndose por tales, los vasos de oro y plata, piedras preciosas, ricos ornamentos, reliquias insignes de santos, una copiosa biblioteca, los ganados con exclusión de sus frutos o partos, los árboles frutales o necesarios al predio, de manera que, cortados, se le deterioraba notablemente.

Esta prohibición, empero, no era absoluta, pues había causas que permitían la enajenación, en concreto: i) la evidente necesidad de la iglesia, como la de pagar las deudas o de reparar la iglesia para evitar su ruina; ii) la manifiesta utilidad de la iglesia, como la enajenación de una cosa para adquirir otra mejor; iii) la piedad, como alimentar a los pobres en una grave necesidad. Cualquiera de ellas era suficiente para la enajenación, pero, además, se requería el cumplimiento de algunas solemnidades, en concreto: i) que precediese el conocimiento y deliberación del capítulo catedralicio para calificar si había justa causa; ii) el

95 Código de Derecho Canónico, 1917, can. 1410: “Constituyen la dote del beneficio ora los bienes que pertenezcan a la misma entidad jurídica, ora prestaciones ciertas y debidas de alguna familia o persona moral, ya ofrendas ciertas y voluntarias de los fieles, que pertenecen al rector del beneficio; ya los llamados derechos de estola, dentro de los límites fijados por el arancel diocesano o por la costumbre legítima, o bien las distribuciones corales, excluida la tercera parte de las mismas si todas las rentas del beneficio consisten en distribuciones corales".

96 Concilio Vaticano II, Decreto Presbyterorum ordinis: 20.

97 Donoso, J. 1848-1849: II, 278-280. 
consentimiento del mismo capítulo, no el simple consejo, por lo que el prelado quedaba vinculado al consentimiento el que, si no se daba, impedía la enajenación por mucho que la deseara el obispo; tratándose de bienes de iglesias inferiores a la catedral y la enajenación la hacía el rector de la misma, la autorización debía darla el obispo; iii) la suscripción por parte del cabildo del acuerdo celebrado por ellos; iv) el consentimiento del Romano Pontífice, lo que en América, por la distancia y difícil acceso a la Silla Apostólica, no se exigía, bastando la aprobación del obispo o del superior respectivo.

El Código dispuso que para la enajenación se requería: i) tasación de la cosa por peritos honrados hecha por escrito; ii) causa justa, es decir, necesidad urgente, o utilidad manifiesta de la Iglesia, o piedad; iii) licencia del superior legítimo, sin la cual era inválida la enajenación (c.1530 $\S 1)$. El superior legítimo a quien correspondía dar la licencia variaba según fuera el valor de la cosa: i) si se trataba de bienes preciosos o de valor superior a las treinta mil liras o francos, el superior legítimo era la Sede Apostólica; ii) si el valor no sobrepasaba las mil liras o francos, el superior legítimo era el ordinario local, oído el consejo de administración, a menos que se tratase de una cosa insignificante, y con el consentimiento de aquellos a quienes interesaba; ii) si el valor oscilaba entre las mil y las treinta mil lira o francos, el superior legítimo era el ordinario del lugar con tal de que obtuviese el consentimiento del cabildo catedral y del consejo de administración, además de aquellos a quienes interesaba (c.1532 § 1-3). Solemnidades todas estas que no sólo había que cumplir tratándose de una enajenación propiamente dicha, "sino también en cualquier contrato del cual puede quedar la Iglesia en peor condición" (c.1533).

Como se puede ver, la sugerencia del prelado de Nicaragua no tuvo mayor acogida; antes bien, la Iglesia fue más celosa con la enajenación de sus bienes, pues, a diferencia de lo que había sucedido en el período indiano, ahora el recurso a la Santa Sede era obligatorio si se trataba de bienes cuya cuantía así lo requería. Y no sólo se siguió exigiendo el consentimiento del cabildo para los bienes que lo requerían según su cuantía, sino que se agregó el consentimiento del consejo de administración.

\section{CONCLUSIONES}

Llegados al final de estas páginas en las que he hecho un primer análisis de los postulata del arzobispo de Guatemala y del obispo de Nicaragua formulados en respuesta a la primera de las consultas que se hizo desde Roma al iniciarse el proceso de codificación del derecho canónico, podemos sintetizarlas en los siguientes puntos:

1. En 1904, año en que se hizo la primera consulta desde Roma acerca de la codificación canónica que se empezaba a preparar, la provincia eclesiástica de Guatemala estaba integrada por el arzobispado de Guatemala y los obispados de Nicaragua, Comayagua, San Salvador y San José de Costa Rica. De ellos, a esta primera consulta romana solo respondieron el arzobispo de Guatemala y el obispo de Nicaragua.

2. Los postulata del arzobispo no fueron numerosos, tan sólo cuatro, referidos a la forma externa del derecho canónico, a la promulgación de las leyes eclesiásticas, a algunos impedimentos matrimoniales y a la usura. Como en materia de impedimentos matrimoniales se refirió, en concreto, a los parentescos por consanguinidad, afinidad, espiritual y legal, en definitiva sus postulata abordaron ocho temas diversos. Se trató de exposiciones razonadas, que no se limitaron a sugerir una reforma concreta, sino que daban las razones de por qué entendía que había que hacer o no hacer una reforma en particular, en las que el prelado hizo gala de una buena formación canónica, con citas a textos del Corpus luris Canonici y del derecho reciente.

3. En sus planteamientos el arzobispo no siempre se mostró claro, en especial en lo referido a la eliminación de algunos grados de parentesco por consanguinidad y afinidad, en los que se remitió a la respuesta que había dado a una consulta anterior de la Santa Sede sobre la eliminación de algunos de estos grados de parentesco como impedimento, pero sin pronunciarse ahora con claridad acerca de dicha eliminación. No obstante ello, Klumper, en el resumen que hizo de los postulata episcoporum, los incluyó junto con los de otros prelados que se manifestaban favorables a su eliminación.

4. En otros aspectos se mostró más bien inmovilista, lo que ocurrió con las preguntas que formuló en relación con la usura en las que manifestó su deseo de que el mutuo con interés se asemejase a esa figura, lo que, en el tiempo en que él escribía sus postulata, era un tema ya superado por la teología moral que afirmaba la licitud de los intereses cobrados con ocasión del contrato de mutuo.

5. En las dos primeras propuestas que formuló, las referidas a la forma externa del derecho canónico y a la promulgación de las leyes eclesiásticas, se mostró buen conocedor del derecho de la Iglesia y también del derecho de los Estados, que al tiempo de sus postulata, ya habían consagrado la codificación como modalidad fijadora del derecho. Se advierte aquí la formación y experiencia jurídicas que había tenido antes de su ordenación sacerdotal.

6. A diferencia de las sugerencias del arzobispo, las del obispo nicaragüense son breves, precisas y apodícticas, sin entrar en mayores razonamientos; tan sólo sugirió lo que le pareció. Fueron sólo cinco propuestas, que mostraron las preocupaciones que más interesaban al prelado en los momentos en que las formuló, producto de las experiencias vividas al frente del obispado.

7. A pesar de su corto número, dos de ellas involucraron al cabildo eclesiástico, señal de que también en Nicaragua, como en otros lugares del continente, su obispo no tenía las mejores relaciones con los canónigos. Otra se refirió a la posibilidad de delegar en algún sacerdote para administrar el sacramento de la confirmación cuyo ministro ordinario era el obispo. En esta sugerencia el obispo se mostró profético, pero hubo que esperar al Concilio Vaticano II y al Código de Derecho Canónico de 1983 para que su sugerencia se hiciera derecho vigente en la Iglesia.

8. Se advierte en el obispo de Nicaragua un prelado celoso de los derechos y prerrogativas de la Iglesia, pues otra de sus sugerencias proponía simplemente abolir el sistema de patronato del que tantos males habían venido a la Iglesia. Y se advierte en el prelado una especial perspicacia para entender los problemas de la Iglesia, lo que se observa en su sugerencia de modificar el sistema beneficial 
especialmente en lo que se refería a las parroquias, un sistema que, cuando el prelado hacía su postulatum, ya había empezado a entrar en crisis. Pero nuevamente hubo que esperar al Concilio Vaticano II para que los padres conciliares, sin eliminarlo del todo, decidieran sustituirlo por otro sistema que permitiera igualmente la digna y congrua sustentación de los clérigos.

\section{BiBLIOGRAFÍA}

Albani, B. 2012. "Nuova luce sulle relazioni tra la Sede Apostolica e le Americhe. La pratica della concessione del 'Pase regio' ai documenti pontifici destinati alle Indie", en C. Fernal (ed.), Eusebio Francesco Chini e il suo tempo. Una riflessione storica: 83-102. Trento: Fondazione Bruno Kessler.

Albani, B. 2014. "Un nuncio per il Nuovo Mundo. Il ruolo della nunciatura di Spagna come istanza di giustizia per i fedeli americani tra Cinque e Seicento", en P. Tusor; M. Sanfilippo (ed.), II papato e le Chiese locale. Studi / The Papacy and the local Churches. Studies: 257-286. Viterbo: Sette Città.

Alonso Lobo, A.; Miguelez Domínguez, L.; Alonso Morán, S. 1963. Comentarios al Código de Derecho Canónico: II. Madrid: Biblioteca de Autores Cristianos.

Alonso Morán, S.; Cabreros de Anta, M. 1964. Comentarios a Código de Derecho Canónico: III. Madrid: Biblioteca de Autores Cristianos.

Álvarez Cora, E. 2005. La teoría de los contratos en Castilla (siglos XVI-XVIII). Madrid: Colegio Nacional de Registradores Propiedad y Mercantiles.

Barrio Gozalo, M. 2004. El real patronato y los obispos españoles del Antiguo Régimen, Madrid: Centro de Estudios Políticos y Constitucionales.

Aubert, R. 1988. "Guatemala", en Dictionnaire d'histoire et de géographie ecclésiastique, XXII: 589-598. Paris.

Barile, N.L. 2008. "Il debattito sul prestito a interesse negli ultim trent'anni tra probabilisti e rigoristi. Un bilancio storiografico". Nuova Rivista Storica 92: 835-874.

Bazzichi, O. 2008. Dall'usura al giusto. L'etica económica della Scuola francescana. Torino: Effatà Editrice.

Bersani, F. 1917."Le fonti del diritto canonico prima della codificazione", Rivista di Diritto Ecclesiastico 10: 23-41.

Boudinhon, A. 1904, 1905. "De la codification du droit canonique", Le Canoniste Contemporain 27: 641-650; 28, 18-23, 76-83, 139-149, 207-215, 302-309, 473-481, 563-568.

Cabreros de Anta, M.; Alonso Lobo, A.; Alonso Morán, S. 1963. Comentarios al Código de Derecho Canónico: I: 106-110. Madrid: Biblioteca de Autores Cristianos.

Calisse, C. 1904. "La codificazione del diritto canonico", Rivista Internazionale di Scienze Sociali 35: 346-365.

Codex luris Canonici. Postulata Episcoporum in ordinem digesta a Rmo. P. Bernardino Klumper O. F. M. Consultore, Romae, Typis Vaticanis, 1905, en Archivio Segreto Vaticano. Codificazione CIC 1917, caja 4.

Conte a Coronata, M. 1940. Interpretatio authentica Codicis Iuris Canonici et circa ipsum Sanctae Sedisi urisprudentia 1916-1940. Taurini, Romae: Domus Editorialis Marietti.

Conte a Coronata, M. 1957. Institutiones iuris canonici ad usum utriusque clero et scholarum. De sacramentis tractatus canonicus, III: De matrimonio et de sacramentalibus. 3ed.: Torino.

Corpus luris Canonici. 1879. 1959. Friedberg, A. E. (ed.). Lipsiae, Graz.

De Leturia, P. 1959. Relaciones entre la Santa Sede e HispanoAmérica 1493-1835, I: Época del real patronato 1493-1800: I. Romae-Caracas.

De Salazar Abrisquieta, J. 1977. “Capacidad e impedimentos matrimoniales”, en Catedráticos de Derecho Canónico de Universidades Españolas, Derecho canónico. Pamplona: Ediciones Universidad de Navarra.

Donoso, J. 1848-1849. Instituciones de derecho canónico americano. Valparaíso: Imprenta de El Mercurio, 2 vols.

Dougnac Rodríguez, A. 2003. Esquema del derecho de familia indiano. Santiago de Chile: Instituto de Historia del Derecho Juan de Solórzano y Pereira.
Fantappiè, C. 2008. Chiesa romana e modernità giuridica, I: L'edificazione del sistema canonistico (1563-1903); II: II Codex luris Canonici (1917), Milano: Giuffrè.

Ferme, B. E. 1998. Introduzione alla storia delle fonti del diritto canonico, I: Il diritto antico fino al Decretum di Graciano, Roma: Mursia. Pontificia Università Lateranense.

Fernández, A. 1995. Compendio de Teología moral. Madrid: Palabra.

Gamba, C. 1997. "Natura, propietà ed usura secondo el ius commune", en Atti del Seminario di studi su diritto alla vita e debito estero (S. Agata dei Goti: 1-2 agosto 1996): 99-128. Napoli: Edizioni Scientifiche Italiane.

Gamba, C. 2004. Licita usura. Giuristi e moralisti tra Medioevo ed età moderna. Roma: Viella Editore.

Gamba, C. 2004. "Natura ed usura, La disputa ottocentesca sulla liccità del préstito ad interese". Rivista di Storia del Diritto Italiano 78: 139-186.

García Barberena, T. 1964. Comentarios al Código de Derecho Canónico: IV. Madrid: Biblioteca de Autores Cristianos.

García y García, A.1967. Historia del derecho canónico, I: El primer milenio. Salamanca: Instituto de Historia de la Teología Española.

Guzmán Brito, A. 1997. Derecho privado romano. Santiago de Chile, Editorial Jurídica de Chile. 2 vols.

Guzmán Brito, A. 2007. "El origen y desarrollo de la idea de codificación del derecho", en A. Guzmán Brito (ed.), El Código Civil de Chile (1855-2005). Trabajos expuestos en el Congreso internacional celebrado para conmemorar su promulgación, Santiago, 3-6 octubre de 2005: 43-99. Santiago: Lexis Nexis.

Guzmán Brito, A. 2000. La codificación civil en Iberoamérica. Siglos XIX y xx. Santiago: Editorial Jurídica de Chile. Hay una segunda edición notablemente ampliada, 2006, con el título Historia de la codificación civil en Iberoamérica. Cizur Menor: Thomson Aranzadi.

Hernáez, F.J. 1895. Colección de bulas, breves y otros documentos relativos a la Iglesia de América y Filipinas: I, 24-25; Bruselas.

Juanos, D. 1936. Compendio de historia de la Ciudad de Guatemala, 3ed. Ciudad de Guatemala.

Llobell, J.; De León, E.; Navarrete, J. 1999. II libro "De processibus" nella codificazione del 1917. Studi e documenti: I: 34. Milano: Giuffrè.

Mansi, J. D., Sacrorum conciliorum nova et amplissima collectio, Sacrosancti Oecumenici Concilii Vaticani, vol. 53.

Metzler, J. (ed.), 1991. America Pontificia. Primi saeculi evangelizationis 1493-1592. Città del Vaticano: Librería Editrice Vaticana. 2 vols.

Munro, J. H. 2003. "The Medieval Origins of the Finantial Revolution: Usury, "Rentes» and Negotiability". The International History Review 25: 505-576.

Ochoa, X. 1966-1987. Leges Ecclesiae post Codicem iuris canonici editae. Roma: Institutum luridicum Claretianum, 6 vols.

"Pio X e la codificazione del diritto canonico", II Contencioso Ecclesiastico 5: 66-68.

Pontificia Commissio pro America Latina. 1999. Acta et decreta Concilii Plenarii Americae Latinae in Urbe celebrati anno Domini MDCCCXCIX, ed. facsimilar. Ciudad del Vaticano: Librería Editrice Vaticana.

Pizzorusso, G.; Sanfilippo, M. 1998. "L'attenzione romana alla Chiesa coloniale Ispano-Americana nell'età di Filippo II", en J. Martínez Millán (ed.), Felipe II (1527-1598). Europa y la monarquía católica: 321-340. Madrid: Parteluz.

Pizzorusso, G. 2014. "Nuovo Mundo cattolico e Papato: Chiesa coloniale, Chiesa missionaria, Chiesa locale (secoli XVI-inizio XIX)", en P. Tusor; M. Sanfilippo (ed.), II papato e le Chiese locale. Studi / ThePapacy and the local Churches. Studies: 205-256. Viterbo: Sette Città.

Ramírez Colom, J. M. 1913. Reseña biográfica del ilustrísimo y reverendísimo señor arzobispo de Santiago de Guatemala, don Ricardo Casanova y Estrada. Ciudad de Guatemala.

Rufini, F. 1905. "La codificazione del diritto ecclesiastico", en Studi di diritto in onore di Vittorio Scialoja: II, 353-391. Milano.

Salinas Araneda, C. 2008. "El primer aporte de los obispos chilenos a la codificación del derecho canónico de 1917: los postulata episcoporum". Revista de Estudios Histórico-Jurídicos 30: 317-342.

Salinas Araneda, C. 2008. "El primer aporte de los obispos chilenos a la codificación del derecho canónico de 1917: los postulata episcoporum acerca del matrimonio". Historia 41: 429-431. 
Salinas Araneda, C. 2009. "Las relaciones Iglesia-Estado en la América indiana: patronato, vicariato, regalismo", en J.G. Navarro Floria (ed.), Estado, derecho y religión en América Latina: 17-52. Buenos Aires: Marcial Pons.

Salinas Araneda, C. 2010. “Le relazioni Chiesa-Stato in America Latina: introduzione storica", en J.G. Navarro Floria; D. Milani (ed.), Diritto e religione in America Latina: 19-67. Bologna: II Mulino.

Salinas Araneda, C. 2015. "La formación de un espacio jurídico transnacional en el siglo xIX a partir del patronato indiano". Rechtsgeschichte, Zeitschrift des Max-Planck-Instituts für europäische Rechtsgeschichte 23: 207-221.

Sanfilippo, M.; Pizzorusso, G. 2004. “L'America iberica e Roma fra Cinque e Seicento: notizie, documenti, informatori", en M. Sanfilippo; A. Koller; G. Pizzorusso (ed.), Gliarchivi della Santa Sede e il mondo Asburgico nella prima Età Moderna: 73-118. Viterbo: Sette Città.

Sartori-Belluco. 1963. Enchiridion canonicum seu Sanctae Sedis responsiones post editum Codicem luris Canonici datae 1917-1963, 11ed., Roma: Bibliotheca Pontificii Athenaei Antoniani.
Tan, E. S. 2005. “Origins and Evolution of the Medieval Church's Usury Laws: Economic Self-Interestor Systematic Theology?". The Journal of European Economic History 34: 263-281.

Tedeschini, G. 2002. I mercanti e il tempo. La società cristiana e il circolo virtuoso della ricchezza fra Medioevo et Età Moderna. Bologna: II Mulino.

Tedeschini, G. 2004. Ricchezza francescana. Dalla povertà volontaria alla società di mercato. Bologna: II Mulino.

Vetulani, A. 1942. "Codex Juris Canonici", en Dictionnaire de Droit Canonique, III: 920. Paris: Librairie Letouzey et Anè.

Viglione, A. 1995. "L'usura secondo Jacques Le Goff", en Educare all'uso responsabile del denaro. La comunità cristiana di fronte al fenómeno dell'usura: 278-281. Roma: Dehoniane.

Villien, A. 1906, 1907, 1908. "Les reformes du droit canonique et les postulata du concile du Vaticain", Le Canoniste Contemporaine 29: 65-74, 209-221, 369-384, 449-463, 554-564, 652-659, 712717; 30: 74-83, 137-147, 220-228, 273-283; 31: 16-23, 207-219, 364-376. 


\section{ANEXOS}

1

Postulata del ARZobispo de Guatemala, Ricardo CASANOVA Y ESTRADA

Guatemala, 17 de agosto de 1904

Archivo Secreto Vaticano, Fondo Commissione (Pontificia) per la codificazione del diritto canonico, caja 96

El arzobispo de Guatemala [impreso]

De Summi Pontificis mandato, Emmus Cardinalis a Secretis Status, literis diei 25 martii proxime elapsi, ab Episcopis catholici orbis exquirebat "an et quaenam, ipsorum sententia, in vigente iure canonico immutatione vel emendation prae ceteris indigeant". En Archiepiscopi de Guatemala hac de re humilis opinio.

\section{DE IURIS CANONICI FORMA EXTERNA}

Quod in sua externa forma ius Ecclesiae immutatione indigeat, manifestum videtur. Partim quippe contentum est voluminibus quae vocari possunt codices $^{98}$ hodierno huius verbi sensu (hispane códigos), quorum partes vel articuli iussa aut declarationes brevi sermone ac praeceptivo proferunt, quorum ordo plus minusve idoneus apparet; partim vero collectionibus quae mere complexus sunt nunc pontificiarum constitutionum, nunc synodorum canonum, nunc resolutionum $S$. romanarum Congregationum, vel generales instructiones pro spirituali, liturgico aut iudiciario regimine Ecclesiae, ordine tantum chronologico disposita. Veneranda effata S. Pontificis dicentis: "cepisse consilium in rem tandem deducendi vota illustrium Ecclesiae Praesulum ut Ecclesiae leges, lucido ordine digestae in unum colligerentur"; effata haec, inquam, sperare sinunt christianum orbem tandem utilitatibus fruiturum codicis vel corporis codicum consilio historico non minus quam philosophico informati, ubi nihil nisi practica auctoritate vigens atque nostrorum temporum conditionem aptarum repetiatur. Tunc iuris Ecclesiae redactio eadem scientifica tractaretur methodo optimisque conditionibus eluceret quibus, uti fertur, nonnulla edicta, praescripta, instructionis a Pio VII, Gregorio XVI, Pío IX pro temporali regimine Status ecclesastici promulgata commendatur.

\section{LEgUM ECCLESIASTICARUM PROMULGATIO}

Pro sacris vero legibus certe desideratur promulgationis ratio authentica, permanens, vere publica, cunctis facile agnoscibilis. Votae sunt canonistarum quaestiones circa S. Congregationis Concilii decisionum vim universaliter obligando: quoad R. et U. Ynquisitionem, Commentariis quibusdam in Const. Apostolicae Sedis, Romae ann. 1883 editis, ap. XXXI haec legimus: "Hinc, cum lex fiat cum promulgatur, decreta Ynquisitionis pro illis tantum valent ad quos diriguntur; pro aliis minime, vel postquam eis constat de legitima promulgatione". Meum non est iudicare de veritate sententiae huiusce et quidem adscriptae ad S. Officii

98 Éste y los siguientes subrayados se encuentran en el texto original. decretum diei 22 decembris 1880 quo authentice declaratur sect. III art. I dictae Constitutionis comprehendere matrimonium, civile dictum, a personis ecclesiaticis attentatum, cuius universalis extensio et efficacia indubia conspicitur. De S. Rituum Congregationis Decretis generalibus nequit esse dubitatio: responsa autem decisiones veetiam in particularibus casibus emissa, frequenter vim habent ob materiae ipsius naturam, generaliter obligandi: disputabile tamen esse potest.

Omnia cuiuscumque generis dubia prorsus tollerentur Collectione quadam authentica legume ecclesiasticarum a S. Sede in luce medita, sit amen dispositions tantum vim universalis legis habente seadem complecterentur: iuris fons unicus foret. Decisiones aliae quae leges sunt iis solummodo ad quos diriguntur in lucem ire poterunt privatarum collection num ope (Acta S. Sedis, Analecta ecca, etc. etc.), optimum que iurisprudentiae thesaurum constituerent.

\section{SUPER MATRIMONII IMPEDIMENTIS}

S. Congregatio S. Oficii ab Episcopis quaerebat, anno 1892, an conveniens iudicarent libere permittere consanguineis quarto gradu, affinibus vero quarto et tertio ex matrimonio, ex illicit autem coniunctione secundo gradui unctis nuptias inire. Uteo tempore exposui, modo opinor per dictorum abolitionem impedimentorum, praesenti christianae societatis conditione, imminutum peccata iri, efficaciusque morum integritatem sanctitatem que matrimonii ese custodienda.

Quoad impedimentum spirituali cognatione proveniens, si eiusdem ratio est reverentia quaedam ex sacramenti susceptione orta, multum profecto ipsum reduci videtur debere. Amplificatio aestimari potest quod can. 1, caus. 30, quaest. 3, dicitur; "quos (omnes cognatione hac utcumque coniunctos) per caeleste sacramentum regeneratio $\mathrm{S}$. Spiritus vincit"; quod proprie tantum dici potest de baptizante et baptizato, confirmante et confirmato. Reverentia huiusmodi supponi quidem debet in masculo baptizato erga feminam quae, necessitatis casu, ipsum aqua regenerationis abluit: tunc grata mens submissaque adolescentis observantia in mulierem quae tantum ei bonum contulit maritalibus ac paternis contraria foret officiis, praestantem viri auctoritatem exigentibus. Ratio haecet pro matrinis quae masculum tenuerunt vi non caret. In laico baptizante sub mission aliqua erga puellam ab illo baptizata certe nequit praesumi, manet tamen reverentia in sacramentalem baptismi characterem cuius collationis ipse fuit instrumentum quique repugnantiam aliqualem cum re uxorial casu dicto habet.

Nulla tamen specialis reverentiae causa inter baptizantem aut susceptorem et parentes baptizanti aut suscepti conspicitur; multo minus talis reverentiae quae ad munia coniugalia oppositionem ferat.

Compaternitas spiritualis quae ex una parte vere spiritualis est, ex altera naturalis non videtur obicem esse debere ad contrahendam, primo soluto vinculo, aliam compaternitatem, futurorum scilicet liberorum commune paternitatem, naturalem pariter ac spiritualem utpote christiano matrimonio profluentem. Ita fideles a susceptoris officio minus forsan retraherentur, expiditiorque in coniugalem statum via cunctis praeberetur. 
De cognationis demum legalis impedimento dici potest eius causam, adoptionem scilicet iuxta civileius romanorum, institutum paene fictitium ac sterile fuisse, ideo nempe quod nimis naturam imitari studuerit. Rarissima ubique, ni fallor, nunc adoptio existit; et si frequentissima esset, tantum abest ut cognationem hanc legalem matrimonio oporteat ese impedimento, ut potius tamquam causa alia impedimenta (si forte exstarent) dispensandi habenda sit; quia necessaria ut plurimum commoratio sub eodem tecto liberorum adoptivorum ac naturalium eiusdem parentis periculum, saltem occasionem, praebere tincontinentiae. Videtur ergo impedimentum hoc prorsus aboleri conveniens esse.

\section{CiRCA USURAM}

Haec proponam consideranda $1^{\circ}$ Estne recta Luc. VI, 35 aliorumque Scripturae sacrae locorum qui hac de re adducuntur intelligentia tenens omnen pecuniae creditae reditum iure divino prohibitum esse? Aliter: Estne usura sacris paginis improbata eadem moralis entitas ac stipulatio quam nunc mutuum cum reditu vocamus? $2^{\circ}$ Estne iure naturali principium aliquod prohibens pecuaniae domino aliquid supra sortem accipere cum mutuarius hoc aliquid libere ac sponte solvat, omni dolo vel coactione exclusa? $3^{\circ}$ Si hodierna usura (a iudaica longe distans) iure naturali et divino exclusa esset potiuss etne Ecclesia consentire, imo probare permissionem a gubernis etiam catholicis factam aliquid supra sortem recipiendi? Guberniorum dominium, eminens nuncupatum (quod hic allegatur) estne verum dominium, imo vero iure privati domini in rebus suis efficacius, vel potius (uti manifestum videtur) suprema procuratio tantum, permittens quidem rei privatae ademptionem, vel uti nunc dicitur expropriationem ob publicam utilitatem, haud tamen aliter quam domina exacte de iusto pretio compensato? An potuisset Ecclesia probare quoque redituum acceptionem etiam (quod plus est) titulo civilis legis non concurrente? $4^{\circ}$ Cuncta haec bene perspecta, foretne conveniens veriorem usurae delicti notionem lege canonica statuere, sic ex. gr. illud definiens: Delictum quo quis alterius ignorantia aut necessitate abutens maiores pecuniarum reditus ab eo extorquet quam lex vel consuetudo sinit?

Guatemalae 17 augusti 1904.

+Richardy, archiep.Guatemalen.

\section{TRADUCCIÓN}

Por mandato del Sumo Pontífice, el eminentísimo cardenal Secretario de Estado, por cartas del día 25 de marzo próximo pasado, pedía el parecer de los obispos del mundo católico "acerca de aquellas materias que, de acuerdo con su parecer, en el derecho canónico vigente necesiten de algún cambio o corrección". He aquí la humilde opinión del arzobispo de Guatemala acerca de esta materia.

\section{SOBRE LA FORMA EXTERNA DEL DERECHO CANÓNICO}

Que, en su forma externa, el derecho de la Iglesia tiene necesidad de cambio, parece evidente. En parte, ciertamente, está contenido en los volúmenes que pueden ser llamados códices en el sentido actual de esta palabra (en español códigos) de los que sus partes o artículos presentan mandatos o declaraciones en estilo breve y preceptivo, cuyo orden aparece más o menos idóneo; en parte, por cierto, en las colecciones que solo contienen ya constituciones pontificias, ya cánones sinodales, ya resoluciones de las sagradas congregaciones romanas o instrucciones generales a favor de lo espiritual, lo litúrgico o el régimen judicial de la Iglesia, dispuestas solamente en orden cronológico. Debe ser respetado lo que lo dice el Sumo Pontífice en el sentido que "se tome el consejo sobre esta materia, en fin, sacándolo de los votos de los ilustrísimos gobernantes de la Iglesia para que las leyes de la Iglesia fuesen reunidas en un solo texto, en un claro orden de distribución"; digo que esto permite esperar que el mundo cristiano gozará de las utilidades de un código o de un cuerpo de códigos informado con un consejo histórico no menos que filosófico, donde nada esté vigente, sino por autoridad práctica y se descubra adaptado a la condición de nuestros tiempos. Entonces, esta misma redacción científica del derecho de la Iglesia que fuese tratada con método, mostrará las óptimas condiciones por las que, como se dice, fueron alabados algunos edictos, preceptos, instrucciones de Pío VII, Gregorio XVI, Pio IX promulgados para el régimen temporal del Estado eclesiástico.

\section{PROMULGaCión DE LAS LEYES ECLESIÁStICAS}

A favor de las sagradas leyes se desea, ciertamente, la promulgación en razón de que sea auténtica, permanente, verdaderamente pública, de fácil conocimiento para todos. Son conocidas entre los canonistas las disputas acerca de la fuerza universal de obligar de las decisiones de la Sagrada Congregación del Concilio; en lo que se refiere a la Romana y Universal Inquisición, leemos en los Comentarios a la Constitución Apostolicae Sedis, editada en Roma el año 1883, ap. XXXI: "A partir de aquí, cuando una ley sea promulgada, los decretos de la Inquisición sólo valen para aquellos a quienes están dirigidos, mínimamente para los otros, o bien después que conste de ellos la legítima promulgación". No me corresponde juzgar sobre la verdad de la sentencia añadida al decreto del Santo Oficio del día 22 de diciembre de 1880 que declara auténticamente que la sección III, artículo I de dicha Constitución comprende el matrimonio llamado civil, atentado por personas eclesiásticas, cuya extensión y eficacia universal se percibe de manifiesto. Acerca de los decretos generales de la Sagrada Congregación de Ritos no puede haber duda: las respuestas o bien las decisiones emitidas en casos particulares, frecuentemente tienen la fuerza de la naturaleza misma de la materia, obligando generalmente: sin embargo, puede ser discutible.

Todas las dudas de cualquier género pueden ser disipadas por una Colección auténtica de leves eclesiásticas editada por la Santa Sede, si es que las disposiciones a las que van unidas tienen la fuerza de leyes universales: la fuente del derecho sería única. Otras decisiones que son leyes que interesan sólo a los que van dirigidas, pueden publicarse en colecciones privadas (Actos de la Santa Sede, 
Compendios, etc.), que constituirían el mejor tesoro de jurisprudencia.

\section{SOBRE LOS IMPEDIMENTOS MATRIMONIALES}

La Sagrada Congregación del Santo Oficio preguntaba a los obispos, en el año 1892, acaso juzgarían conveniente permitir el matrimonio libremente a los consanguíneos en cuarto grado, a los parientes por afinidad en cuarto y tercer grado originada por matrimonio, por afinidad por ilícita unión en segundo grado. Como expuse en ese momento, tengo la opinión de que por la abolición de dichos impedimentos, en la presente condición de la sociedad cristiana, serían rebajados como pecados, en circunstancias de que deben ser custodiadas la integridad de las costumbres y la santidad del matrimonio.

En cuanto al impedimento proveniente de parentesco espiritual, si la razón del mismo es la reverencia a la recepción del sacramento, mucha utilidad debe verse para reducir el mismo. La ampliación se puede considerar según el canon 1, causa 30, de la cuestión 3 [del Decreto de Graciano] según el cual "a los que (todos los unidos por este parentesco) vence la regeneración del Santo Espíritu por el celeste sacramento"; lo que solamente puede decirse propiamente del bautizante y del bautizado, del confirmante y del confirmado. De esta manera, reverencia debe suponer ciertamente en el varón bautizado toda mujer que, en caso de necesidad, purifica al mismo con el agua de la regeneración: entonces la mente grata y sumisa de la observancia adolescente a una mujer que le llevó el bien fuera contraria a los oficios maritales y paternales y a las exigencias de la autoridad del varón. Esta razón no carece de fuerza a favor de las madrinas que tuvieron un varón. En un laico bautizante sin duda no está en estado de presumirse alguna inferioridad hacia la niña por él bautizada; permanece, sin embargo, la reverencia al carácter sacramental del bautismo de cuya colación él mismo fue instrumento y porque tiene alguna repugnancia con la materia matrimonial el caso dicho.

Sin embargo, no se percibe ninguna causa especial de reverencia entre el bautizante o encargado y los padres del bautizado o receptor; mucho menos tal reverencia que haga oposición a las obligaciones conyugales.

La compaternidad espiritual que, por una parte, es verdaderamente espiritual, por otra natural, no se ve que deba ser óbice para contraer, disuelto el primer vínculo, otra compaternidad, a saber la común paternidad de los futuros hijos, natural e igualmente espiritual como fluye del matrimonio cristiano. Así los fieles quizá se retraerán menos del oficio de encargado, y se presentaría más expedito el estado conyugal como una vía para todos.

Finalmente, sobre el impedimento de parentesco legal puede decirse que su causa, esto es la adopción conforme al derecho civil de los romanos, había sido establecida casi ficticia y estéril, por lo que evidentemente se habría buscado imitar demasiado la naturaleza. Muy raramente en algún lugar, si no me engaño, existe la adopción; y si fuese muy frecuente, sólo está lejos de que convenga ser impedimento del matrimonio por parentesco legal, antes bien que sea tenido como causa de dispensar otros impedimentos (si por casualidad existieran); porque la necesaria residencia ordinaria bajo el mismo techo de los hijos adoptivos y los naturales de un mismo padre ofrecería muchísimo peligro, al menos ocasión de incontinencia. Parece conveniente, por lo tanto, que este impedimento sea abolido completamente.

\section{ACERCA DE LA USURA}

Propongo que se deben considerar: ¿Acaso de Lucas 6, 35 y de otros lugares de la Sagrada Escritura que acerca de esta materia son citados no se ha de entender que todo interés por préstamo de dinero está prohibido por derecho divino? Por otra parte: ¿Acaso la usura no está condenada en las páginas sagradas como una misma entidad moral que la estipulación que ahora llamamos mutuo con interés? $2^{\circ}$ ¿Acaso el principio de derecho natural prohíbe a uno aceptar algo de dinero en dominio sobre capital puesto a ganancias con mutuario que pague libremente y por propia voluntad, excluido todo dolo o coacción? $3^{\circ}$ Si la actual usura (largamente distante de la judaica) que está excluida por derecho natural y divino, podría la Iglesia consentir, antes bien aprobar el permiso hecho por los gobiernos católicos de recibir algo sobre capital puesto a ganancias? El dominio de los gobiernos, declarado eminente (lo que aquí se alega) ¿es acaso verdadero dominio, antes bien verdadero derecho privado de dominio eficaz en sus cosas, o más bien (como parece manifiesto) solo una suprema administración, que permite el despojo de las cosas privadas o, como se dice ahora, una expropiación por utilidad pública, sin embargo cuando el dueño es compensado exactamente con el justo precio? ¿Acaso hubiese podido la Iglesia aprobar la aceptación de intereses (lo que lo más) con un título de la ley civil no concurrente? $4^{\circ}$ Bien examinado todo esto ¿no sería conveniente establecer en la ley canónica una noción más legítima del delito de usura, así, por ejemplo, definirlo: "delito por el cual alguien que abusa de la ignorancia de otro o de su necesidad le exige mayores intereses de dinero que la ley o la costumbre permite"?

Guatemala, 17 de agosto de 1904.

+Ricardo, arzobispo de Guatemala.

\section{2}

\section{Postulata del obispo de NicARAgua}

Sin lugar, sin fecha

Archivo Secreto Vaticano, Fondo Commissione (Pontificia) per la codificazione del diritto canonico, caja 96.

\section{DE ECCLESIAE LEGIBUS IN UNUM REDIGENDIS}

\section{I}

Ut Episcopi unum vel alium sacerdotem delegare possint ad confirmandum si propter infirmitatem vel locorum distantias ipsimet non potuerint.

II

Ut Episcopi si praevideant ex interventione auctoritatis civilis Capitulum in Vicarium Capitularem electurum 
clericum minime Ecclesiae congruentem, ipsi possint ante mortem illum nominare uti pluries $\mathrm{S}$. Sedes ex privilegio concessit.

\section{III}

Jus patronatus quaecumque sit eius origo, et speciatim laicale, omnino censeo abolendum, experientia enim docemur quot mala exinde Ecclesiae obvenerint.

$$
\text { IV }
$$

Videtur inmutanda theoria beneficiorum saltem parochialium tum ex difficultate perpetuitatis tum ex interventione Gubernii Civilis.

\section{$\mathrm{V}$}

Ut Episcopi de consensus Capituli iure suo possint res quascumque ecclesiasticas alienare si necessitas vel periculum usurpationis urgeat.

Rimesis dall'Arciv. di Guatemala

\section{TRADUCCIÓN}

Sobre las leyes de la Iglesia que han de ser reducidas a un solo Código$$
\text { I }
$$

Que los obispos puedan delegar en uno u otro sacerdote para que confirmen, si por causa de una enfermedad o por las distancias de los lugares, ellos mismos no hubiesen podido.

$$
\text { II }
$$

Que los obispos, si prevén que, por intervención de la autoridad civil, el Capítulo habrá de elegir para Vicario Capitular a un clérigo mínimamente congruente con la Iglesia, que puedan ellos mismos nombrar, antes de morir, así como las más de las veces concede la Santa Sede por privilegio.

III

El derecho de patronato, cualquiera que sea su origen, y particularmente el laical, pienso que debe ser completamente abolido, pues la experiencia enseña los males que desde él han venido a la Iglesia.

\section{IV}

Parece oportuno que sea cambiada la teoría de los beneficios, al menos los parroquiales, ya por la dificultad de la perpetuidad, ya por la intervención del gobierno civil.

$$
\mathrm{V}
$$

Que los obispos, fuera del consentimiento del capítulo, puedan por derecho propio, enajenar cualquiera de las cosas eclesiásticas si urge la necesidad o el peligro de usurpación.

Enviado por el arzobispo de Guatemala. 